1 Cellular management of Zinc in group B Streptococcus supports bacterial

2 resistance against metal intoxication and promotes disseminated infection

3 Matthew J. Sullivan, Kelvin G. K. Goh and Glen C. Ulett*

4 School of Medical Sciences, and Menzies Health Institute Queensland, Griffith

$5 \quad$ University, Parklands, Australia 4222

6 Article Type: Major Article

7 Running Head: Zinc stress in Streptococcus agalactiae

8 Word count: Abstract 242, Text 4344

9 Display Items: 7 Figures

10 Supplemental Material: 1 Figure, 3 Tables

11 \# Corresponding author: Professor Glen C. Ulett, School of Medical Science, and

12 Menzies Health Institute Queensland, Griffith University, Gold Coast, QLD 4222,

13 Email: g.ulett@griffith.edu.au ; T: +61 756780765 ; F: +61 755632236 
14 Abstract: Zinc (Zn) is an essential trace element for normal bacterial physiology

15 but divergently, can intoxicate bacteria at high concentrations. Here, we define

16 the molecular systems for Zn detoxification in Streptococcus agalactiae, also

17 known as group B Streptococcus, and examine the effects of resistance to $\mathrm{Zn}$

18 stress on virulence. We compared the growth of wild-type bacteria and mutants

19 deleted for the $\mathrm{Zn}$ exporter, $c z c D$, and the response regulator, $s c z A$, using $\mathrm{Zn}-$

20 stress conditions in vitro. Macrophage antibiotic protection assays and a mouse

21 model of disseminated infection were used to assess virulence. Global bacterial

22 transcriptional responses to $\mathrm{Zn}$ stress were defined by RNA-sequencing and

23 qRTPCR. $c z c D$ and $s c z A$ enabled $S$. agalactiae to survive $Z n$ stress, with the

24 putative CzcD efflux system activated by SczA. Additional genes activated in

25 response to $\mathrm{Zn}$ stress encompassed divalent cation transporters that contribute

26 to regulation of $\mathrm{Mn}$ and Fe homeostasis. In vivo, the $c z c D$-sczA Zn-management

27 axis supported virulence in the blood, heart, liver and bladder. Additionally, several

28 genes not previously linked to Zn stress in any bacterium, including most notably,

$29 \operatorname{arcA}$ for arginine deamination also mediated resistance to $\mathrm{Zn}$ stress; representing

30 a novel molecular mechanism of bacterial resistance to metal intoxication. Taken

31 together, these findings show that $S$. agalactiae responds to $\mathrm{Zn}$ stress by sczA

32 regulation of $c z c D$, with additional novel mechanisms of resistance supported by

33 arcA, encoding arginine deaminase. Cellular management of $\mathrm{Zn}$ stress in $S$.

34 agalactiae supports virulence by facilitating bacterial survival in the host during

35 systemic infection. Keywords: Metallobiology; Molecular microbiology; Microbial

36 pathogenesis; S. agalactiae; Metal ions; Zinc efflux; Bacterial pathogenesis; $c z c D$ 


\section{Importance Statement}

38 Streptococcus agalactiae, also known as group B streptococcus, is an opportunistic

39 pathogen that causes various diseases in humans and animals. This bacterium has

40 genetic systems that enable Zinc $(\mathrm{Zn})$ detoxification in environments of metal stress, but

41 these systems remain largely undefined. Using a combination of genomic, genetic and

42 cellular assays we show that this pathogen controls $\mathrm{Zn}$ export through $\mathrm{CzcD}$ to manage

43 Zn stress, and utilizes a system of arginine deamination never previously linked to metal

44 stress responses in bacteria to survive metal intoxication. We show that these systems

45 are crucial for survival of $S$. agalactiae in vitro during $Z n$ stress and also enhance

46 virulence during systemic infection in mice. These discoveries establish new molecular

47 mechanisms of resistance to metal intoxication in bacteria; we suggest these

48 mechanisms are likely to operate in other bacteria as a way to sustain microbial survival

49 in conditions of metal stress, including in host environments. 


\section{Introduction}

51 Inside living cells, zinc $(\mathrm{Zn})$ is an essential cofactor for metalloenzymes $(1,2)$ but

52 is toxic at high concentrations, as can be encountered by bacteria inside

53 phagocytes $(3,4)$. The double-edged sword of essentiality and toxicity of $\mathrm{Zn}$ to

54 bacteria is a burgeoning area of research due to potential for antimicrobial

55 applications (5-7). In the host, bacterial pathogens employ distinct mechanisms

56 for internalizing essential $\mathrm{Zn}(8,9)$, and in turn, the host can restrict $\mathrm{Zn}$ availability

57 as an antimicrobial strategy (10). Phagocytes can mobilise cellular $\mathrm{Zn}$ to expose

58 internalized bacteria to metal concentrations that are antimicrobial $(5,11,12)$.

59 Host-driven $\mathrm{Zn}$ intoxication (defined as an excess of extracellular $\mathrm{Zn}$ ) of bacterial

60 pathogens can involve ablation of uptake of essential Mn (13), a compromised

61 bacterial response to oxidative stress (14), or disrupted central carbon

62 metabolism (15). Some bacteria can evade metal intoxication by mechanisms

63 that involve metal efflux (16).

64 In streptococci, a specific genetic system manages $\mathrm{Zn}$ homeostasis by regulating

65 metal import and export $(13,17)$. In Pneumococcus and Streptococcus

66 pyogenes, systems for $\mathrm{Zn}$ efflux pair a $\mathrm{Zn}$-sensing transcriptional response

67 regulator $(s c z A)$ with a $Z n$ efflux transporter, encoded by $c z c D(17,18)$. Here, we

68 studied Zn management in Streptococcus agalactiae, also known as group B

69 Streptococcus, which is an important opportunistic pathogen that has undefined

$70 \mathrm{Zn}$ detoxification systems and is associated with distinct disease aetiologies

71 compared to other streptococci. We establish a role for CzcD, as well as other

72 novel factors, in mediating $S$. agalactiae resistance to $\mathrm{Zn}$ stress and virulence. 


\section{Materials and Methods}

\section{Bacterial strains, plasmids and growth conditions}

75 S. agalactiae, E. coli and plasmids used are listed in Supplementary Table 1. S.

76 agalactiae was routinely grown in Todd-Hewitt Broth (THB) or on $\mathrm{TH}$ agar (1.5\%

77 w/v). E. coli was grown in Lysogeny Broth (LB) or on LB agar. Media were

78 supplemented with antibiotics (spectinomycin (Sp) $100 \mu \mathrm{g} / \mathrm{mL}$; chloramphenicol

$79(\mathrm{Cm}) 10 \mu \mathrm{g} / \mathrm{mL})$, as indicated. Growth assays used $200 \mu \mathrm{L}$ culture volumes in $96-$

80 well plates (Greneir) sealed using Breathe-Easy® membranes (Sigma Aldrich)

81 and measured attenuance $(D$, at $600 \mathrm{~nm})$ using a ClarioSTAR multimode plate

82 reader (BMG Labtech). Media for growth assays were THB and a modified

83 Chemically-Defined Medium (CDM) (9) (with 1 $\mathrm{g} / \mathrm{L}$ glucose, $0.11 \mathrm{~g} / \mathrm{L}$ pyruvate and

$8450 \mu \mathrm{g} / \mathrm{L} \mathrm{L-cysteine),} \mathrm{supplemented} \mathrm{with} \mathrm{Zn}$ (supplied as $\mathrm{ZnSO}_{4}$ ) as indicated. For

85 attenuance baseline correction, control wells without bacteria were included for

$86 \mathrm{Zn}$ in media alone.

87 DNA extraction and genetic modification of S. agalactiae

88 Plasmid DNA was isolated using miniprep kits (QIAGEN), with modifications for S. agalactiae as described elsewhere (19). Deletion of $c z c D$ (CHF17_00567 /

90 CHF17_RS02855 = ASZ00854.1) was constructed by allelic exchange with a Cm

91 cassette using pHY304aad9 as described previously (20). Deletions in $s c z A$ and

$92 \operatorname{arcA}$ were generated similarly but without $\mathrm{Cm}$-markers. Constructs, complement

93 plasmids and primers are listed in Supplementary Table 2. Constructs for sczA

94 and $\operatorname{arcA}$ deletions were made with DNA synthesised in pUC57 by Genscript 
95 (USA) prior to subcloning into pHY304aad9. Mutants were validated by PCR

96 using primers external to the mutation site and DNA sequencing.

\section{Expression system for mCherry in S. agalactiae}

98 Plasmid pGU2665 was designed for expressing mCherry in trans in S. agalactiae

99 from the pCP25 promoter (21) cloned into pDL278 (22) (Supplementary Figure

100 1). Plasmid DNA was manipulated and ligation reactions were performed

101 essentially as described elsewhere (19). We verified pGU2665 by restriction

102 analysis and sequencing using primers listed in Supplementary Table 2.

103 Sequence reads were mapped and assembled using Sequencher software.

104 Electroporation of $S$. agalactiae and selection of transformants was performed as 105 described previously (20). Plasmid stability assays were performed as described 106 previously (19).

107 RNA extraction, qRTPCR

108 For Zn exposure experiments, $1 \mathrm{~mL}$ overnight THB cultures were back-diluted $1091 / 100$ in $100 \mathrm{~mL}$ of THB (prewarmed at $37^{\circ} \mathrm{C}$ in $250 \mathrm{~mL}$ Erlenmeyer flasks)

110 supplemented with $0.25,0.5,1.0$ or $1.5 \mathrm{mM} \mathrm{Zn}$. Cultures were grown shaking 111 (200rpm) at $37^{\circ} \mathrm{C}$; after exactly $2.5 \mathrm{~h}, 10-50 \mathrm{~mL}$ volumes containing approximately 112500 million mid-log bacteria were harvested; RNA was preserved and isolated as 113 described previously (23). RNA quality was analysed by RNA LabChip using GX 114 Touch (Perkin Elmer). RNA (1000ng) was reverse-transcribed using Superscript 115 IV according to manufacturer's instructions (Life Technologies) and cDNA was 116 diluted 1:50 in water prior to qPCR. Primers (Supplementary Table 2) were 117 designed using Primer3 Plus $(24,25)$ to quantify transcripts using Universal 
118 SYBR Green Supermix (Bio-Rad) using a Quantstudio 6 Flex (Applied

119 Biosystems) system in accordance with MIQE guidelines (26). Standard curves were generated using five point serial dilutions of genomic DNA (5-fold) from WT S. agalactiae 874391 (27). Expression ratios were calculated using $\mathrm{C}_{\mathrm{T}}$ values

122 and primer efficiencies as described elsewhere (28) using dnaN, encoding DNA 123 polymerase III $\beta$-subunit as housekeeper.

\section{Whole bacterial cell metal content determination}

125 Metal content in cells was determined as described (14) with minor modifications.

126 Cultures were prepared essentially as described for RNA extraction, qRTPCR with the following modifications; THB medium was supplemented with $0.25 \mathrm{mM}$ $\mathrm{ZnSO}_{4}$ or not supplemented (Ctrl), and following exposure for $2.5 \mathrm{~h}$, bacteria were

129 harvested by centrifugation at $4122 \times \mathrm{g}$ at $4^{\circ} \mathrm{C}$. Cell pellets were washed 3 times

130 in PBS + 5mM EDTA to remove extracellular metals, followed by 3 washes in

131 PBS. Pelleted cells were dried overnight at $80^{\circ} \mathrm{C}$ and resuspended in $1 \mathrm{~mL}$ of

$13232.5 \%$ nitric acid and incubated at $95^{\circ} \mathrm{C}$ for $1 \mathrm{~h}$. The metal ion containing 133 supernatant was collected by centrifugation (14,000 x g, 30min) and diluted to a 134 final concentration of $3.25 \%$ nitric acid for metal content determination using 135 inductively coupled plasma optical emission spectroscopy (ICP-OES). ICP-OES 136 was carried out on an Agilent 720 ICP-OES with axial torch, OneNeb concentric 137 nebulizer and Agilent single pass glass cyclone spray chamber. The power was $1381.4 \mathrm{~kW}$ with $0.75 \mathrm{~L} / \mathrm{min}$ nebulizer gas, $15 \mathrm{~L} / \mathrm{min}$ plasma gas and $1.5 \mathrm{~L} / \mathrm{min}$ auxiliary 139 gas flow. Zn was analyzed at $213.85 \mathrm{~nm}, \mathrm{Cu}$ at $324.75 \mathrm{~nm}$, Fe at $259.94 \mathrm{~nm}, \mathrm{Mn}$ at $140257.61 \mathrm{~nm}$ with detection limits at $<1.1 \mathrm{ppm}$. The final quantity of each metal was 
141 normalised using dry weight biomass of the cell pellet prior to nitric acid

142 digestion, expressed as $\mu \mathrm{g} . \mathrm{g}^{-1}$ dry weight. Baseline concentrations were

143 determined to be $10.9 \pm 0.07 \mu \mathrm{M} \mathrm{Zn}$ in THB medium, and $0.11 \pm 0.03 \mu \mathrm{M} \mathrm{Zn}$ in

144 CDM medium from at least three independent assays.

145 RNA sequencing and bioinformatics

146 Cultures were prepared as described above for RNA extraction, qRTPCR.

147 RNase-free DNase-treated RNA that passed Bioanalyzer 2100 (Agilent) analysis

148 was used for RNA sequencing (RNA-seq) using the Illumina NextSeq 500

149 platform. We used TruSeq library generation kits (Illumina, San Diego,

150 California). Library construction consisted of random fragmentation of the poly $(A)$

151 mRNA, followed by cDNA production using random primers. The ends of the

152 cDNA were repaired and A-tailed, and adaptors were ligated for indexing (with up

153 to 12 different barcodes per lane) during the sequencing runs. The cDNA libraries

154 were quantitated using qPCR in a Roche LightCycler 480 with the Kapa

155 Biosystems kit (Kapa Biosystems, Woburn, Massachusetts) prior to cluster

156 generation. Clusters were generated to yield approximately $725 \mathrm{~K}-825 \mathrm{~K}$

157 clusters $/ \mathrm{mm}^{2}$. Cluster density and quality was determined during the run after the

158 first base addition parameters were assessed. We ran paired-end $2 \times 75-b p$

159 sequencing runs to align the cDNA sequences to the reference genome. For data

160 preprocessing and bioinformatics, STAR (version 2.7.3a) was used to align the

161 raw RNA sequencing fastq reads to the WT S. agalactiae 874391 reference

162 genome (27). HTSeq-count, version 0.11.1, was used to estimate transcript

163 abundances (29). DESeq2 was then used to normalized and test for differential 
164 expression and regulation. Genes that met certain criteria (i.e. fold change of >

$165 \pm 2.0$, q value of $<0.05)$ were accepted as significantly altered (30). Raw and

166 processed data were deposited in Gene Expression Omnibus (accession no.

167 GSE161127).

168 Mammalian cell culture

169 J774A.1 murine macrophages or U937 human monocyte-derived macrophages

170 (MDMs) were grown in RPMI and seeded $\left(10^{5}\right)$ into the wells of a 96-well tissue

171 culture-treated plate (Falcon) essentially as described elsewhere (31, 32), except

172 that U937 MDMs were differentiated by exposure to $30 \mathrm{ng} / \mathrm{mL}$ phorbol $12-$

173 myristate 13 -acetate (PMA) for $48 \mathrm{~h}$ and cells subsequently rested in media

174 without PMA for $72 \mathrm{~h}$ to enhance morphological and phenotypic markers of MDMs

175 (33). A multiplicity of infection (MOI) of 100 bacteria:macrophage for 1 h was used

176 in RPMI without antibiotics. Non-adherent bacteria were removed by five washes

177 of $200 \mu \mathrm{L}$ PBS using a Well Wash Versa (Thermo Scientific). RPMI containing

178 250U/mL penicillin, streptomycin (Gibco) and 50 $\mathrm{gg} / \mathrm{mL}$ gentamicin (Sigma-

179 Aldrich) were used for antibiotic protection assays to quantify intracellular

180 bacteria as described previously (32). At $1 \mathrm{~h}, 24 \mathrm{~h}$ or $48 \mathrm{~h}$ after infection,

181 monolayers were washed five times with $200 \mu \mathrm{L}$ PBS and lysed by brief exposure

182 to $50 \mu \mathrm{L}$ of $2 \%$ trypsin and $0.02 \%$ Triton-X-100 (10min) prior to dilution with $150 \mu \mathrm{L}$

183 PBS and estimation of CFU/mL by serial dilution and plate counts on agar.

184 Fluorescence microscopy

185 Fifty thousand J774A.1 cells were seeded into 8-well LabTek II chamber slides

186 (Nunc) and infected with mCherry-S. agalactiae for 24h. Non-adherent bacteria 
were removed by three washes of $200 \mu \mathrm{L}$ PBS and fixed for $15 \mathrm{~min}$ at $37^{\circ} \mathrm{C}$ using $4 \%$ paraformaldehyde (w/vol). Monolayers were stained for $\mathrm{Zn}^{2+}$ using $5 \mu \mathrm{M}$

189 FluoZin-3 ${ }^{\mathrm{TM}}$ AM (Life Technologies) for $30 \mathrm{~min}$ at $37^{\circ} \mathrm{C}$, and subsequently, for 190 DNA using Hoechst 33258 for 5 min. Fixed stained cells were washed twice in 191 PBS and mounted using n-propyl gallate ( $n-p g)$ mounting medium $(0.2 \%$ n-pg in 9:1 glycerol/PBS). mCherry-S. agalactiae was visualized using a Zeiss Axiolmager.M2 microscope (Carl Zeiss Microlmaging) fitted with PlanApochromat X20/0.8 and X63/1.40 objective lenses and an AxioCam MRm Rev.3 camera. Images of cells were captured with 63HE, 44 and 49 filter sets (to detect mCherry (587nm, 610nm), FluoZin ${ }^{T M}-3$ (494nm, 518nm) and Hoechst 33258 $(352 \mathrm{~nm}, 461 \mathrm{~nm})$ fluorescence, respectively, with excitation and emission spectra listed consecutively for each) and Zen Pro (version 2) software.

\section{Animals and Ethics statement}

201 intravenous challenge with $10^{7}$ S. agalactiae as described elsewhere (34). This study was carried out in accordance with the guidelines of the Australian National

203 Health and Medical Research Council. The Griffith University Animal Ethics

204 Committee reviewed and approved all experimental protocols for animal usage 205 according to the guidelines of the National Health and Medical Research Council 206 (approval: MSC/01/18/AEC).

\section{Statistical methods}

208 All statistical analyses used GraphPad Prism V8 and are defined in respective

209 Figure Legends. Statistical significance was accepted at $P$ values of $\leq 0.05$. 


\section{Results}

\section{Excess Zn impedes S. agalactiae growth and disturbs cell physiology}

212 Initial assays analyzed the growth of wild-type (WT) S. agalactiae strain 874391

213 (ST-17; Serotype III) in a nutrient-rich Todd-Hewitt broth (THB) supplemented

214 with moderate $(0.5 \mathrm{mM})$, high $(1.0 \mathrm{mM})$ and excess $(1.5 \mathrm{mM})$ levels of $\mathrm{Zn}$. High

215 and excess $\mathrm{Zn}(\geq 1 \mathrm{mM})$ delayed exponential growth of the WT with significant

216 attenuation of the growth rate and final biomass yield (Figure 1A). An isogenic

$217 \Delta c z c D$ mutant strain was significantly more susceptible to $\mathrm{Zn} \geq 1 \mathrm{mM}$ (Figure $1 \mathrm{~A}$ ).

218 Full-length $c z c D$ supplied in trans to the mutant $(\triangle c z c D:: c z c D)$ restored growth to

219 WT levels in Zn stress (Figure 1A). Spot test assays of the bacteria on agar

220 containing $0,0.5,1.0$ and $1.5 \mathrm{mM} \mathrm{Zn}$ showed similar levels of susceptibility of the

221 WT and $\triangle c z c D$ strains (Figure 1B) on solid medium (Figure 1B) compared to

222 planktonic growth.

224 We next used a nutrient limited medium to examine $\mathrm{Zn}$ stress in $\mathrm{S}$. agalactiae in

225 a modified Chemically Defined minimal Medium (CDM), which is likely to more

226 closely reflect a host-environment (nutrient-limited). CDM contained low basal

227 levels of $\mathrm{Zn}(0.11 \pm 0.03 \mu \mathrm{M})$, as determined by ICP-OES. Growth assays of $S$.

228 agalactiae in $\mathrm{CDM} \pm \mathrm{Zn}$ supplementation revealed markedly enhanced $\mathrm{Zn}$ -

229 induced toxicity compared to THB, with Zn totally bacteriostatic to all strains at

$230 \quad 0.5 \mathrm{mM}$ (Figure $1 \mathrm{C}$ ). Similar to $\mathrm{THB}$, growth of the $\triangle c z c D$ mutant was significantly

231 inhibited compared to the WT upon exposure to $\geq 0.1 \mathrm{mM}$ in CDM (Figure 1C). 


\section{Regulation of Zn-efflux in S. agalactiae}

233 The capacity of $\mathrm{Zn}$ stress to induce expression of $c z c D$ for $\mathrm{Zn}$ export was

234 examined by analyzing mid-log phase $S$. agalactiae exposed to $0.25-1.5 \mathrm{mM} \mathrm{Zn}$

235 for 2.5h prior to qRTPCR quantification of $c z c D$. $c z c D$ was significantly

236 upregulated in response to $\mathrm{Zn}$ (3-fold - 18.9-fold) in a manner that was titratable

237 with the $\mathrm{Zn}$ concentration (Figure $2 \mathrm{~A}$ ); and consistent with a role for $\mathrm{CzcD}$ in

238 responding to extracellular $Z n$. Interestingly, we identified a candidate gene,

239 divergent from $c z c D$, that encodes a putative $\mathrm{Zn}$-responsive activator in the TetR-

240 family of transcription factors, termed streptococcal $\underline{\mathbf{c z}} c D \underline{\text { Activator, or }}$ szcA (35).

241 Similar to $\triangle c z c D$ S. agalactiae, a mutant deficient in $s c z A(\triangle s c z A)$ was markedly

242 more susceptibility to Zn stress compared to WT in both nutrient-rich and -limited

243 conditions; the attenuation was restored by complementation in trans (Figure 1).

245 To confirm the role of SczA as a Zn-responsive activator of $c z c D$ expression, we

246 quantified $c z c D$ mRNA in $\triangle s c z A S$. agalactiae exposed to $0.25 \mathrm{mM} \mathrm{Zn}$ (sub-

247 inhibitory; to enable comparisons independent of metabolic state, and alleviate

248 potential bias from any discordant Zn stress between WT and mutants with

249 varied resistance phenotypes). Deletion of $s c z A$ significantly perturbed activation

250 of $c z c D$ in response to $\mathrm{Zn}$ (Figure $2 \mathrm{~B}$ ), consistent with previous reports of SczA

251 functioning as a Zn-dependent activator of $c z c D$ in S. pyogenes and $S$.

252 pneumoniae $(17,18)$. 


\section{Intracellular $\mathrm{Zn}$ content in S. agalactiae during $\mathrm{Zn}$ stress}

255 We analyzed accumulation of $\mathrm{Zn}$ ions within the bacteria following $\mathrm{Zn}$ stress by

256 using growth conditions equivalent to those for transcriptional experiments; WT,

$257 \Delta c z c D$ and $\triangle s c z A$ S. agalactiae were exposed to $0.25 \mathrm{mM} \mathrm{Zn}$ for $2.5 \mathrm{~h}$ prior to

258 quantifying intracellular metal content by ICP-OES. In the WT strain, Zn stress

259 caused accumulation of intracellular Zn (52.1 vs $38.8 \mu \mathrm{g} \mathrm{Zn/g} \mathrm{dry} \mathrm{weight)}$

260 compared to non-exposed control cultures. In addition, intracellular Zn contents

261 in $\triangle c z c D$ and $\triangle s c z A$ mutants exposed to the same conditions were significantly

262 enhanced (84.3 and $67.5 \mu \mathrm{g} \mathrm{Zn/g} \mathrm{dry} \mathrm{weight,} \mathrm{respectively)} \mathrm{compared} \mathrm{to} \mathrm{WT} \mathrm{in} \mathrm{Zn}$

263 stress or control incubations of the mutant strains without Zn (Figure 2C). These

264 findings are consistent with roles for $\mathrm{CzcD}$ and $\mathrm{SczA}$ as mediators of $\mathrm{Zn}$ efflux.

266 Resistance of intracellular S. agalactiae to $\mathrm{Zn}$ stress in macrophages

267 To determine if $Z n$ efflux systems support survival of $S$. agalactiae in phagocytic

268 cells, we used murine macrophages and human monocyte-derived macrophage-

269 like cells in antibiotic protection assays at $1 \mathrm{~h}, 24 \mathrm{~h}$ and $48 \mathrm{~h}$ of incubation. Viable

270 intracellular S. agalactiae were reduced in number over the time course in human

271 and murine cells, but no significant differences between WT, $\triangle c z c D$ and $\triangle s c z A$

272 strains were detected (Figure 3A). To examine host-mediated $\mathrm{Zn}$ release inside

273 phagocytic cells, we developed a system for expressing mCherry in $S$.

274 agalactiae. We used this in concert with a Zn-binding fluorophore (FluoZin ${ }^{\mathrm{TM}}-3$ 
275 AM) to visualize intracellular S. agalactiae inside J774A.1 cells. Despite no effect

276 of Zn efflux mutants on survival, we observed that S. agalactiae induced robust

277 mobilization of $\mathrm{Zn}$ inside host cells at the $24 \mathrm{~h}$ timepoint, compared to non-

278 infected control incubations (Figure 3B) as shown by enhanced detection and

279 distribution of free $\mathrm{Zn}$ using FluoZin ${ }^{\mathrm{TM}}-3 \mathrm{AM}$.

280

\section{S. agalactiae $\mathrm{Zn}$ efflux systems contribute to virulence in vivo}

282 To examine the contribution of $\mathrm{Zn}$ efflux to in vivo colonization of $S$. agalactiae,

283 we used a murine model of disseminated infection to monitor tissue and

284 bloodstream burdens (34). In mice that were challenged intravenously with $10^{7}$

285 bacteria and monitored for bacterial load, we detected significantly fewer $\triangle c z c D$

286 mutant in the liver $(P=0.046)$ and bladder $(P=0.025)$, compared to the WT at 24

287 h post-inoculation (Figure 4A). No differences were observed between counts of

288 the WT and $\triangle c z c D$ mutant in the brain, blood, heart, lungs, kidneys, or spleen

289 (data not shown). In addition, significantly fewer $\Delta s c z A$ mutant were recovered

290 from the blood $(P=0.039)$ and heart $(P=0.032)$ compared to the WT (Figure 4B),

291 indicating a modest but statistically significant role for cellular management of $\mathrm{Zn}$

292 via $c z c D$ and $s c z A$ in supporting disseminated infection in vivo.

\section{S. agalactiaeZn stress transcriptome reveals new mediators of resistance}

295 The transcriptome of $S$. agalactiae in response to $\mathrm{Zn}$ stress was used to define

296 the global response of this organism to externally applied Zn. RNA-Seq identified

297567 genes that were differentially expressed upon exposure to $0.25 \mathrm{mM} Z \mathrm{n}$ (229 
up-, 238 down-regulated; \pm 2 -fold, P-adj <0.05, $\mathrm{n}=4$ biological replicates) in WT $S$.

299 agalactiae (Figure 5A and Supplementary Table 3). In addition to up-regulation of

$300 c z c D$, we detected up-regulation of several putative nickel (Ni) and manganese

301 (Mn) transport loci (nikABCD, $m n t H 2$, and $m t s A B C$, respectively), and down-

302 regulation of an iron $(\mathrm{Fe})$ efflux system (fetAB) and Zn-importing adcA (Figure

303 5B). Interestingly, some these transport genes were recently implicated in $S$.

304 agalactiae survival against host-derived calprotectin (36), which mediates $\mathrm{Zn}$

305 starvation, as opposed to Zn intoxication.

307 To provide functional insight into the observed changes in metal transporters, we

308 analysed cellular metal content of $S$. agalactiae during Zn stress, for other

309 second row transition metals, including $\mathrm{Mn}, \mathrm{Fe}, \mathrm{Ni}$ and $\mathrm{Cu}$. We saw significant

310 reduction in Mn levels, enhanced cellular Fe, no difference in Cu levels, and $\mathrm{Ni}$

311 was below the detection limit $(0.8 \mathrm{ppm})$ (Figure $5 \mathrm{C})$, when comparing cultures of

312 WT bacteria under $\mathrm{Zn}$ stress $(0.25 \mathrm{mM})$ to non-supplemented controls (THB 313 media only).

315 In addition to metal transporters, we detected modulation of several metabolism-

316 related gene clusters that have not previously been linked to $\mathrm{Zn}$ stress in

317 bacteria, encompassing de novo nucleotide synthesis and import systems

318 (carAB, pyrB, pyrFEC, pur genes, uraA, nrdFIA, guaC) and riboflavin synthesis

319 (ribDEAH) loci (Figure 5 and Supplementary Table 3). Interestingly, a putative

320 arginine deaminase system (ADI), encoded by the arcABCD genes, was 
321 significantly up-regulated (21-29-fold) under Zn intoxication (arcA highlighted in

322 Figure $5 \mathrm{~B})$. The $\operatorname{arc} A B C$ genes encode arginine deaminase (ArcA), ornithine

323 carbamoyltransferase $(\mathrm{ArcB})$ and carbamate kinase (ArcC), with arcD encoding

324 an ornithine/arginine antiporter. This system functions to produce ammonia and

325 ATP from the conversion of arginine to ornithine, as characterised in $S$.

326 pneumoniae (37) and is responsive to numerous stimuli (38). We generated an

327 isogenic $\triangle a r c A$ mutant to examine a potential role for $\mathrm{ADI}$ in $\mathrm{Zn}$ stress resistance

328 in $S$. agalactiae. Comparing the growth of the $\triangle \operatorname{arcA}$ mutant to WT in nutrient-rich

$329 \mathrm{THB}+1 \mathrm{mM} \mathrm{Zn}$ and nutrient-limiting $\mathrm{CDM}+0.1 \mathrm{mM} \mathrm{Zn}$ (conditions in which

$330 \Delta c z c D / \Delta s c z A$ strains were perturbed) revealed significant attenuation of the

$331 \Delta$ arcA strain for growth under Zn stress (Figure 6), noting a modest reduction in

332 growth of the $\triangle$ arcA strain vs WT in control conditions (without added Zn).

333 Finally, S. agalactiae modulated several genes encoding classical virulence

334 and/or immunogenic factors in response to $\mathrm{Zn}$ intoxication, including the cyl gene

335 cluster cyIXDG-acp-cyIZABEFIJK (encoding $\beta$-hemolysin/cytolysin) (2.5-4.3-fold

336 down), IrrG (25-fold up, leucine rich repeat protein), and ess $A B C$ (11-22-fold

337 down, Type VII secretion system) (Supplementary Table 3). We also note that

$338 \sim 20 \%$ of all transcripts $(114 / 567)$ that were differentially regulated in response to

$339 \mathrm{Zn}$ intoxication are predicted to encode hypothetical proteins of unknown

340 function, some of which were up- or down-regulated up to 29 fold. These

341 observations represent a significant pool of targets for further studies in

342 dissecting bacterial responses to $\mathrm{Zn}$ stress. 


\section{Discussion}

344 This study establishes a key role for cellular management of intracellular Zn levels

345 in $S$. agalactiae, via $c z c D, s c z A$ and additional mediators including $\operatorname{arcA}$, in

346 conferring an ability to resist $\mathrm{Zn}$ intoxication to the bacteria. These findings

347 provide new insight into the molecular mechanisms of virulence used by this

348 pathogen to survive in stressful environmental conditions resulting from elevated

349 metal ion levels, such as within phagocytes during infection in a host. In

350 characterising the $\mathrm{Zn}$ efflux systems of $S$. agalactiae in detail, the findings of the

351 present study support prior findings from work on other streptococci $(17,18)$; for

352 example, our characterisation of regulatory functions of $S C Z A$ that enable cellular

353 management of $\mathrm{Zn}$ in $\mathrm{S}$. agalactiae are consistent with prior findings reported for

354 S. pyogenes (17). These prior observations include that $\mathrm{Zn}$ stress upregulates $\mathrm{Zn}$

355 efflux via $c z c D$ and shuts down Zn uptake via adcA (39), with direct effects on the

356 control of intracellular Zn content. Importantly, the Zn stress-response global

357 transcriptome of $S$. agalactiae defined in the current study also elucidates other

358 metal ion transporters and novel additional targets that have not previously been

359 linked to $\mathrm{Zn}$ intoxication in any bacteria. A model of the $\mathrm{Zn}$ stress response in $\mathrm{S}$.

360 agalactiae based on the findings of this study is shown in Figure 7.

362 Systems for $\mathrm{Zn}$ acquisition in $\mathrm{S}$. agalactiae enable survival of the organism under

$363 \mathrm{Zn}$ deficient conditions (9), and confer resistance to calprotectin-mediated metal

364 ion starvation (36) which acts to withhold multiple metals such as $\mathrm{Mn}$ and $\mathrm{Zn}$ from

365 bacteria in the host (40). Our Zn intoxication transcriptional analyses identify 
numerous metal transporters that are differentially regulated, including nik $A B C D$

367 and $m t s A B C$, predicted to transport $\mathrm{Ni}$ and $\mathrm{Mn}$, respectively. Given that $\mathrm{Ni}$ and

368 Mn import genes have been implicated in bacterial survival during calprotectin

369 stress (36), it is possible that nik and $m$ ts genes respond to altered cellular levels

370 of other metals (rather than $\mathrm{Zn}$ ) that occur as a consequence of $\mathrm{Zn}$ intoxication.

372 In our study, levels of cellular Mn were perturbed during $\mathrm{Zn}$ intoxication. This

373 coincided with corresponding up-regulation of $m n t H 2$ and $m t s A B C$ transcription,

374 encoding putative Mn transporters. Interestingly, some, but not all S. agalactiae

375 strains possess two genes encoding proteins homologous to NRAMP-type MntH

376 transporters; $m$ mtH $($ CHF17_00875 = ASZ01148.1) contributes to acid stress

377 responses (41), however a role for mntH2 (CHF17_02002 = ASZ02237.1) has

378 not been determined. In addition, S. agalactiae elevated Fe levels in response to

379 Zn stress, coinciding with down-regulation of a putative Fe export system

380 encoded by fetA-fetB. Contrastingly, Cu levels and expression of $\operatorname{cop} A$ (encoding

381 a putative Cu transporter) were unaffected in S. agalactiae exposed to Zn stress.

382 Collectively, these data show broader dysregulation of metal management in $S$.

383 agalactiae undergoing $\mathrm{Zn}$ intoxication beyond $\mathrm{Zn}$ itself, encompassing $\mathrm{Mn}$ and

384 Fe, consistent with a prior report in pneumococci (14). Future examination of the

385 roles of the $\mathrm{Ni}, \mathrm{Mn}, \mathrm{Fe}$ and $\mathrm{Cu}$ transport in $\mathrm{S}$. agalactiae in the setting of bacterial

386 metal stress and in models of infection would therefore be of interest.

388 The finding that numerous core metabolic pathways in S. agalactiae are impacted 
by Zn stress, including some related to synthesis of purines, pyrimidines,

390 riboflavin and dNTPs, underscores the critical nature of $\mathrm{Zn}$ management for

391 maintenance of basic cellular processes in the bacteria. The arginine deaminase

392 system was among the most differentially regulated gene clusters, undergoing

393 20-30-fold enhanced expression during Zn stress. Remarkably, arcA-deficient S.

394 agalactiae exhibited heightened sensitivity to Zn stress, establishing a novel role

395 for this system in streptococcal resistance to metal ion intoxication. The precise

396 molecular mechanisms that underpin how this system renders the bacterial cell

397 resistant to $\mathrm{Zn}$ intoxication requires further definition but arginine deaminase

398 typically converts arginine to ammonia, ATP and ornithine; overproduction of one

399 of these may support bacterial survival during Zn stress. A recent study identified

400 arginine deaminase as a key factor in resistance to antibiotics and biofilm

401 formation in S. pyogenes (42). Numerous prior studies have reported elevated

402 expression of arc genes in $S$. agalactiae in response to acid stress (43), human

403 serum (44), blood (45), or amniotic fluid (46). This suggests important but yet to

404 be defined roles for arginine deaminase in virulence of $S$. agalactiae. Together

405 with the findings of the current study, these observations suggest that arginine

406 deaminase supports the ability of $S$. agalactiae to respond to diverse stressors in

407 addition to $\mathrm{Zn}$ intoxication.

408

409 Analysis of the role for $\mathrm{Zn}$ efflux systems of $S$. agalactiae in pathogenesis showed

410 no contribution to bacterial survival in macrophages. This finding is surprising in

411 the context of a prior study of $S$. pneumoniae $\operatorname{scz} A$ (that is functionally analogous 
412 to $S$. agalactiae $s c z A$ ), which reported a major role for Zn cellular management

413 via $s c z A$ in the intracellular survival of the bacteria in human macrophages (35).

414 We confirmed the generation of a robust $\mathrm{Zn}$ mobilization response in the host

415 cells following $S$. agalactiae infection but observed equivalent fitness of mutants

416 for Zn management compared to WT for survival in murine and human

417 macrophages. Considering the conserved nature of szcA between streptococci, it

418 is plausible that these mutants might be attenuated in other phagocytes such as

419 neutrophils, as described for $S$. pyogenes (17), noting a need for further

420 examination of differences in metal ion resistance phenotypes among

421 streptococcal species.

423 The discovery of attenuation for colonization in a mouse model of disseminated

424 infection in the $S$. agalactiae mutants in $\mathrm{Zn}$ management systems in this study

425 establishes a role for $\mathrm{Zn}$ stress in disease pathogenesis due to this organism. The

426 attenuations observed for the $c z c D^{-}$and $s c z A^{-}$mutants in the liver and bladder,

427 and the blood and heart, respectively, were not dramatic according to the tissue

428 bacterial loads subsequent to blood challenge; however, the attenuations were

429 statistically significant; and the phenotypes observed were also specific to these

430 tissues because multiple other tissue-types that were analysed had equivalent

431 numbers of WT bacteria and mutants. Considered together, these findings point

432 to tissue-specific effects of the ability to manage $\mathrm{Zn}$ stress in $\mathrm{S}$. agalactiae

433 colonization of the mammalian host. Prior studies have shown more dramatic

434 effects of $c z c D$ and $s c z A$ mutations in reducing bacterial virulence in mouse 
435 models of infection. For example, $c z c D$ mutation rendered S. pyogenes non-

436 lethal in a subcutaneous infection model in mouse (17). czcD mutation attenuated

437 S. pneumoniae 2.6-fold for survival in the lungs of mice following intranasal

438 challenge compared to WT bacteria (47). Evaluating the current findings in the

439 context of these prior studies highlights the differences in experimental designs

440 viz. types of infection models, bacterial species and outcome measures that

441 would likely influence any potential degree of attenuation in mutants $(17,35,47)$.

442 More broadly, this highlights the importance of evaluating the roles of individual

443 mediators such as $\mathrm{CzcD}$, SczA and ArcA in appropriate experimental models that

444 are designed to parallel natural infection in the human host. For S. agalactiae, for

445 example, exploration of the role of resistance to $\mathrm{Zn}$ stress in colonization of the

446 female genital tract (48), and the brain (49) would be of interest given the

447 propensity of this pathogen to cause these infections in humans (50).

449 In conclusion, this study identifies new mediators of $\mathrm{Zn}$ cellular management in $S$.

450 agalactiae, and shows that resistance to $\mathrm{Zn}$ stress in this pathogen contributes to 451 colonization in the host. Future examination of these mediators, and their role

452 survival of $S$. agalactiae and other bacterial pathogens in relevant settings of

453 infection will be important to more fully understand microbial resistance to metal

454 intoxication and it influence on virulence and pathogenesis. 


\section{Acknowledgments}

457 We thank Michael Crowley and David Crossman of the Heflin Centre for

458 Genomic Science Core Laboratories, University of Alabama at Birmingham

459 (Birmingham, AL) for RNA sequencing. We thank Timothy Barnett who provided

460 pLZ12 containing cloned mCherry. We also thank Lahiru Katupitiya and Dean

461 Gosling for excellent technical assistance and Ryan Stewart at the School of

462 Environment Analytical Chemistry Core Facility, Griffith University, for ICP-OES.

463 This work was supported by a Project Grant from the National Health and

464 Medical Research Council (NHMRC) Australia (APP1146820 to GCU). 


\section{References}

467 1. Watly J, Potocki S, Rowinska-Zyrek M. 2016. Zinc Homeostasis at the

$468 \quad$ Bacteria/Host Interface-From Coordination Chemistry to Nutritional

$469 \quad$ Immunity. Chemistry 22:15992-16010.

470 2. Osman D, Cavet JS. 2008. Copper homeostasis in bacteria. Adv Appl

$471 \quad$ Microbiol 65:217-47.

472 3. Chandrangsu P, Rensing C, Helmann JD. 2017. Metal homeostasis and 473 resistance in bacteria. Nature Reviews Microbiology 15:338-350.

474 4. German N, Doyscher D, Rensing C. 2013. Bacterial killing in macrophages and amoeba: do they all use a brass dagger? Future Microbiol 8:1257-64.

476 5. Djoko KY, Ong CL, Walker MJ, McEwan AG. 2015. The Role of Copper

477 and Zinc Toxicity in Innate Immune Defense against Bacterial Pathogens.

$478 \quad$ J Biol Chem 290:18954-61.

479 6. Ladomersky E, Petris MJ. 2015. Copper tolerance and virulence in $480 \quad$ bacteria. Metallomics 7:957-64.

481 7. Besold AN, Culbertson EM, Culotta VC. 2016. The Yin and Yang of 482 copper during infection. Journal of Biological and Inorganic Chemistry $483 \quad 21: 137-44$

484 8. Bayle L, Chimalapati S, Schoehn G, Brown J, Vernet T, Durmort C. 2011. 485 Zinc uptake by Streptococcus pneumoniae depends on both AdcA and 486 AdcAll and is essential for normal bacterial morphology and virulence. Mol Microbiol 82:904-16. 
9. Moulin P, Patron K, Cano C, Zorgani MA, Camiade E, Borezee-Durant E, Rosenau A, Mereghetti L, Hiron A. 2016. The Adc/Lmb System Mediates Zinc Acquisition in Streptococcus agalactiae and Contributes to Bacterial Growth and Survival. J Bacteriol 198:3265-3277.

10. Zygiel EM, Nolan EM. 2018. Transition Metal Sequestration by the HostDefense Protein Calprotectin. Annu Rev Biochem 87:621-643.

11. Kapetanovic R, Bokil NJ, Achard ME, Ong CL, Peters KM, Stocks CJ, Phan MD, Monteleone M, Schroder K, Irvine KM, Saunders BM, Walker MJ, Stacey KJ, McEwan AG, Schembri MA, Sweet MJ. 2016. Salmonella employs multiple mechanisms to subvert the TLR-inducible zinc-mediated antimicrobial response of human macrophages. FASEB J 30:1901-12.

12. Achard Maud ES, Stafford Sian L, Bokil Nilesh J, Chartres J, Bernhardt Paul V, Schembri Mark A, Sweet Matthew J, McEwan Alastair G. 2012. Copper redistribution in murine macrophages in response to Salmonella infection. Biochem J 444:51-57.

13. McDevitt CA, Ogunniyi AD, Valkov E, Lawrence MC, Kobe B, McEwan AG, Paton JC. 2011. A molecular mechanism for bacterial susceptibility to zinc. PLoS Pathog 7:e1002357.

14. Eijkelkamp BA, Morey JR, Ween MP, Ong CL, McEwan AG, Paton JC, McDevitt CA. 2014. Extracellular zinc competitively inhibits manganese uptake and compromises oxidative stress management in Streptococcus pneumoniae. PLoS ONE 9:e89427. 
510 15. Ong CL, Walker MJ, McEwan AG. 2015. Zinc disrupts central carbon metabolism and capsule biosynthesis in Streptococcus pyogenes. Scientific Reports 5:10799.

513 16. Hassan KA, Pederick VG, Elbourne LD, Paulsen IT, Paton JC, McDevitt CA, Eijkelkamp BA. 2017. Zinc stress induces copper depletion in Acinetobacter baumannii. BMC Microbiol 17:59.

516 17. Ong CL, Gillen CM, Barnett TC, Walker MJ, McEwan AG. 2014. An antimicrobial role for zinc in innate immune defense against group A streptococcus. J Infect Dis 209:1500-8.

18. Kloosterman TG, van der Kooi-Pol MM, Bijlsma JJ, Kuipers OP. 2007. The novel transcriptional regulator SczA mediates protection against $\mathrm{Zn}^{2+}$ stress by activation of the $\mathrm{Zn}^{2+}$-resistance gene $\mathrm{czcD}$ in Streptococcus pneumoniae. Mol Microbiol 65:1049-63.

19. Sullivan MJ, Ulett GC. 2018. Stable Expression of Modified Green Fluorescent Protein in Group B Streptococci To Enable Visualization in Experimental Systems. Appl Environ Microbiol 84.

526 20. Ipe DS, Ben Zakour NL, Sullivan MJ, Beatson SA, Ulett KB, Benjamin WHJ, Davies MR, Dando SJ, King NP, Cripps AW, Schembri MA, Dougan G, Ulett GC. 2015. Discovery and Characterization of Human-Urine agalactiae. Infect Immun 84:307-19. 
531 21. Jensen PR, Hammer K. 1998. The sequence of spacers between the

532 consensus sequences modulates the strength of prokaryotic promoters.

533 Appl Environ Microbiol 64:82-7.

534 22. LeBlanc DJ, Lee LN, Abu-Al-Jaibat A. 1992. Molecular, genetic, and

535 functional analysis of the basic replicon of pVA380-1, a plasmid of oral

$536 \quad$ streptococcal origin. Plasmid 28:130-45.

537 23. Sullivan MJ, Leclercq SY, Ipe DS, Carey AJ, Smith JP, Voller N, Cripps

538 AW, Ulett GC. 2017. Effect of the Streptococcus agalactiae Virulence

539 Regulator CovR on the Pathogenesis of Urinary Tract Infection. J Infect

$540 \quad$ Dis $215: 475-483$.

541 24. Untergasser A, Cutcutache I, Koressaar T, Ye J, Faircloth BC, Remm M, 542 Rozen SG. 2012. Primer3--new capabilities and interfaces. Nucleic Acids

$543 \quad$ Res 40:e115.

544 25. Untergasser A, Nijveen H, Rao X, Bisseling T, Geurts R, Leunissen JA. 545 2007. Primer3Plus, an enhanced web interface to Primer3. Nucleic Acids $546 \quad$ Res 35:W71-4.

547 26. Bustin SA, Benes V, Garson JA, Hellemans J, Huggett J, Kubista M, 548 Mueller R, Nolan T, Pfaffl MW, Shipley GL, Vandesompele J, Wittwer CT. 549 2009. The MIQE guidelines: minimum information for publication of 550 quantitative real-time PCR experiments. Clin Chem 55:611-22.

551 27. Sullivan MJ, Forde BM, Prince DW, Ipe DS, Ben Zakour NL, Davies MR, 552 Dougan G, Beatson SA, Ulett GC. 2017. Complete Genome Sequence of 

Genome Announcements 5.

555 28. Pfaffl MW. 2001. A new mathematical model for relative quantification in real-time RT-PCR. Nucleic Acids Res 29:e45.

557 29. Anders S, Pyl PT, Huber W. 2015. HTSeq--a Python framework to work with high-throughput sequencing data. Bioinformatics 31:166-9.

559 30. Love MI, Huber W, Anders S. 2014. Moderated estimation of fold change and dispersion for RNA-seq data with DESeq2. Genome Biol 15:550.

31. Acharya D, Sullivan MJ, Duell BL, Goh KGK, Katupitiya L, Gosling D, Chamoun MN, Kakkanat A, Chattopadhyay D, Crowley M, Crossman DK, Schembri MA, Ulett GC. 2019. Rapid Bladder Interleukin-10 Synthesis in

Response to Uropathogenic Escherichia coli Is Part of a Defense Strategy

567 32. Leclercq SY, Sullivan MJ, Ipe DS, Smith JP, Cripps AW, Ulett GC. 2016. strain and beta-hemolysin/cytolysin that mediates cytotoxicity, cytokine

571 33. Valdes Lopez JF, Urcuqui-Inchima S. 2018. Synergism between phorbol12-myristate-13-acetate and vitamin D3 in the differentiation of U937 cells to monocytes and macrophages. Morphologie 102:205-218. 
574 34. Sullivan MJ, Ulett GC. 2020. Evaluation of hematogenous spread and ascending infection in the pathogenesis of acute pyelonephritis due to group B streptococcus in mice. Microb Pathog 138:103796.

35. Martin JE, Edmonds KA, Bruce KE, Campanello GC, Eijkelkamp BA, Brazel EB, McDevitt CA, Winkler ME, Giedroc DP. 2017. The zinc efflux activator SczA protects Streptococcus pneumoniae serotype 2 D39 from intracellular zinc toxicity. Mol Microbiol 104:636-651.

36. Burcham LR, Le Breton Y, Radin JN, Spencer BL, Deng L, Hiron A, Ransom MR, Mendonca JDC, Belew AT, El-Sayed NM, Mclver KS, Kehl-

Fie TE, Doran KS. 2020. Identification of Zinc-Dependent Mechanisms

37. Schulz C, Gierok P, Petruschka L, Lalk M, Mader U, Hammerschmidt S.

38. Shabayek S, Spellerberg B. 2017. Acid Stress Response Mechanisms of

593 39. Ong CY, Berking O, Walker MJ, McEwan AG. 2018. New Insights into the Infection. Infect Immun 86. 
40. Corbin BD, Seeley EH, Raab A, Feldmann J, Miller MR, Torres VJ, Anderson KL, Dattilo BM, Dunman PM, Gerads R, Caprioli RM, Nacken W, Chazin WJ, Skaar EP. 2008. Metal chelation and inhibition of bacterial growth in tissue abscesses. Science 319:962-5.

41. Shabayek S, Bauer R, Mauerer S, Mizaikoff B, Spellerberg B. 2016. A streptococcal NRAMP homologue is crucial for the survival of Streptococcus agalactiae under low pH conditions. Mol Microbiol 100:589606.

42. Freiberg JA, Le Breton Y, Harro JM, Allison DL, Mclver KS, Shirtliff ME. 2020. The Arginine Deiminase Pathway Impacts Antibiotic Tolerance during Biofilm-Mediated Streptococcus pyogenes Infections. mBio 11.

43. Santi I, Grifantini R, Jiang SM, Brettoni C, Grandi G, Wessels MR, Soriani M. 2009. CsrRS regulates group B Streptococcus virulence gene expression in response to environmental $\mathrm{pH}$ : a new perspective on vaccine development. J Bacteriol 191:5387-97.

44. Yang Q, Zhang M, Harrington DJ, Black GW, Sutcliffe IC. 2011. A proteomic investigation of Streptococcus agalactiae reveals that human serum induces the $\mathrm{C}$ protein beta antigen and arginine deiminase. Microbes Infect 13:757-60.

45. Mereghetti L, Sitkiewicz I, Green NM, Musser JM. 2008. Extensive adaptive changes occur in the transcriptome of Streptococcus agalactiae (group B streptococcus) in response to incubation with human blood. PLoS ONE 3:e3143. 
619 46. Sitkiewicz I, Musser JM. 2009. Analysis of growth-phase regulated genes in Streptococcus agalactiae by global transcript profiling. BMC Microbiol 9:32.

622

47. Eijkelkamp BA, Morey JR, Neville SL, Tan A, Pederick VG, Cole N, Singh PP, Ong CY, Gonzalez de Vega R, Clases D, Cunningham BA, Hughes CE, Comerford I, Brazel EB, Whittall JJ, Plumptre CD, McColl SR, Paton JC, McEwan AG, Doble PA, McDevitt CA. 2019. Dietary zinc and the control of Streptococcus pneumoniae infection. PLoS Pathog 15:e1007957.

48. Carey AJ, Tan CK, Mirza S, Irving-Rodgers H, Webb RI, Lam A, Ulett GC. 2014. Infection and cellular defense dynamics in a novel 17beta-estradiol murine model of chronic human group B streptococcus genital tract colonization reveal a role for hemolysin in persistence and neutrophil accumulation. J Immunol 192:1718-31.

49. Lembo A, Gurney MA, Burnside K, Banerjee A, de los Reyes M, Connelly JE, Lin WJ, Jewell KA, Vo A, Renken CW, Doran KS, Rajagopal L. 2010. Regulation of CovR expression in Group B Streptococcus impacts bloodbrain barrier penetration. Mol Microbiol 77:431-43.

50. Edwards MS, Baker CJ. 2018. 119 - Streptococcus agalactiae (Group B Streptococcus), p 723-729.e1. In Long SS, Prober CG, Fischer M (ed), Principles and Practice of Pediatric Infectious Diseases (Fifth Edition) doi:https://doi.org/10.1016/B978-0-323-40181-4.00119-5. Elsevier. 


\section{Figures Legends}

643 Figure 1. Comparison of the growth WT $S$. agalactiae, $\triangle c z c D$ and $\triangle S c z A$

644 isogenic mutants and complemented strains. A, Growth curves of 874391 and

645 mutant strains as indicated, in Todd-Hewitt broth (THB) supplemented with 0,

$6460.5,1.0$ and $1.5 \mathrm{mM} \mathrm{Zn.} \mathrm{B,} \mathrm{Analysis} \mathrm{of} \mathrm{growth} \mathrm{of} S$. agalactiae strains on solid TH

647 medium with increasing $\mathrm{Zn}$ concentrations by serial dilution and droplets on agar.

648 Composite images are merged from multiple agar plates. C, Growth curves of

649874391 and mutant strains as indicated, in Chemically Defined Medium (CDM)

650 supplemented with $0,0.1,0.25$ and $0.5 \mathrm{mM} \mathrm{Zn.} \mathrm{Data} \mathrm{shown} \mathrm{are} \mathrm{mean}$

651 measurements of attenuance ( $D$; at $600 \mathrm{~nm})$ from 3-4 independent experiments,

652 bars show S.E.M. Attenuance measurements used well-scan mode with a $3 \mathrm{~mm}$

$6535 \times 5$ scan matrix, 5 flashes per point and path length correction of $5.88 \mathrm{~mm}$,

654300 rpm agitation, every 30min

655

656 Figure 2. Expression analysis of $c z c D$ and intracellular $\mathrm{Zn}$ content in $S$

657 agalactiae strains. A, Expression ratio of $c z c D$ quantified by qRTPCR in THB

658 medium containing $0.25,0.5,1.0$ and $1.5 \mathrm{mM} \mathrm{Zn}$, compared to THB without $\mathrm{Zn}$.

$659 \mathrm{~B}$, Relative $c z c D$ transcripts were quantified in WT and $\triangle s c z A$ strains with and

660 without $\mathrm{Zn}$ supplementation. C, Intracellular accumulation of $\mathrm{Zn}$ was compared

661 with and without $\mathrm{Zn}$ supplementation in WT, $\triangle s c z A$ and $\triangle c z c D$ strains. Ratios in

662 A were calculated as described previously (28) using $\mathrm{C}_{\mathrm{T}}$ values, primer

663 efficiencies and housekeeping dnaN. In B and C, Ctrl $=\mathrm{THB}+0 \mathrm{mM} ;+\mathrm{Zn}=\mathrm{THB}$

$664+0.25 \mathrm{mM} \mathrm{Zn}$. Bars show means and S.E.M from 3-4 independent experiments 
and compared by One-way ANOVA with Holm-Sidak multiple comparisons $\left({ }^{* *} \mathrm{P}<\right.$ $\left.0.01 ;{ }^{* * *} \mathrm{P}<0.001\right)$.

Figure 3. Interactions of $S$. agalactiae with macrophages and consequential strains and mouse (J774A.1) or human (U937 monocyte-derived macrophage-

671 like) macrophages, with surviving bacteria quantified at 0, 1, 24 and 48 hours

672 post infection (h.p.i). Data are means and S.E.M of 4-5 independent experiments.

$673 \mathrm{~B}$, Fluorescence imaging of the release of free $\mathrm{Zn}$ (detected using FluoZin ${ }^{\text {TM }}$-3

674 AM) by J774A.1 cells infected with WT S. agalactiae expressing mCherry from 675 pGU2665, compared to non-infected J774A.1 cells at $24 \mathrm{~h}$ post inoculation. DNA was stained using Hoechst 33258. Scale bars $=10 \mu \mathrm{m}$.

Figure 4. Virulence of WT (grey circles), $\triangle c z c D$ (green diamonds) and $\triangle S c z A S$.

679 agalactiae (orange triangles) in a mouse model of disseminated infection.

680 C57BL/6 mice (6-8 weeks old) were intravenously injected with $10^{7}$ bacteria;

681 bacteremia and disseminated spread to the heart $(A)$, liver, and bladder $(B)$ were 682 monitored at $24 \mathrm{~h}$ post infection. CFU were enumerated and counts were 683 normalized using tissue mass in $\mathrm{g}$. Lines and bars show median and interquartile 684 ranges and data are pooled from 3 independent experiments each containing $\mathrm{n}=10$ mice with mutant strains compared using Mann-Whitney U-tests to WT

686 colonization data ( $\left.{ }^{*} \mathrm{P}<0.05,{ }^{* *} \mathrm{P}<0.01\right)$. 
688

689

690

691

692

Figure 5. Transcriptomic analysis of $S$. agalactiae in Zn stress. A, Volcano plot showing data from RNASeq analysis of WT S. agalactiae cultures containing $0.25 \mathrm{mM} \mathrm{Zn} \mathrm{compared} \mathrm{to} \mathrm{non-exposed} \mathrm{controls.} \mathrm{Transcripts} \mathrm{up-} \mathrm{or} \mathrm{down-}$ regulated in response to $\mathrm{Zn}(n=4,> \pm 2$-fold, FDR $<0.05)$ are highlighted in red and blue, respectively. Dotted lines show False discovery rate (FDR; q-value) and fold-change cut-offs. Grey points indicate genes that were unchanged. Selected genes are identified individually with black lines. B, Expression of selected genes from RNASeq analyses showing mean Fragments $\underline{\text { Per Kilobase }}$ of transcript per Million mapped reads (FPKM) values for each condition, with predicted function as indicated. Data were compared with DESeq2 ( ${ }^{*}$-adj $<$ 0.05 and \pm 2 -fold). C, Intracellular accumulation of $\mathrm{Mn}, \mathrm{Fe}$ and $\mathrm{Cu}$ were compared with and without Zn supplementation in WT S. agalactiae using ICP-OES. Bars show means and S.E.M from 3-4 independent experiments and compared by unpaired $t$-tests $\left({ }^{* *} \mathrm{P}<0.01 ;{ }^{* * *} \mathrm{P}<0.001\right)$.

Figure 6. Comparison of the growth WT S. agalactiae and an $\triangle \operatorname{arcA}$ isogenic mutant in under $\mathrm{Zn}$ stress in $\mathrm{A}$, nutritive THB medium $\pm 1 \mathrm{mM} \mathrm{Zn}$ and $\mathrm{B}$, limiting CDM medium $\pm 0.1 \mathrm{mM} Z \mathrm{n}$, versus unexposed controls. Data shown are mean measurements of attenuance ( $D$; at $600 \mathrm{~nm})$ from 3-4 independent experiments, bars show S.E.M and compared using AUC followed by one way ANOVA and Holm-Sidak multiple comparisons $\left({ }^{*} \mathrm{P}<0.05 ;{ }^{* *} \mathrm{P}<0.01 ;{ }^{* * *} \mathrm{P}<0.001\right)$. 
710 Figure 7. Summary of selected S. agalactiae responses to $\mathrm{Zn}$ intoxication. S.

711 agalactiae senses elevated intracellular $\mathrm{Zn}$ to co-ordinate enhanced CzcD

712 expression via the $\mathrm{Zn}$-sensing SczA regulator. Zn stress results in a number of

713 notable changes including differential expression of metal transporters, altered

$714 \mathrm{Zn}, \mathrm{Mn}$ and Fe cellular pools and metabolic pathways encompassing arginine

715 deaminase, de novo purine and pyrimidine syntheses and dNTP synthesis. Red

716 coloring and arrows indicate up-regulation (+ 2-10-fold; ++ 10-20 fold, +++ >20-

717 fold) or down-regulation (-2-10-fold; --- >20 fold) of a transcript or process. 

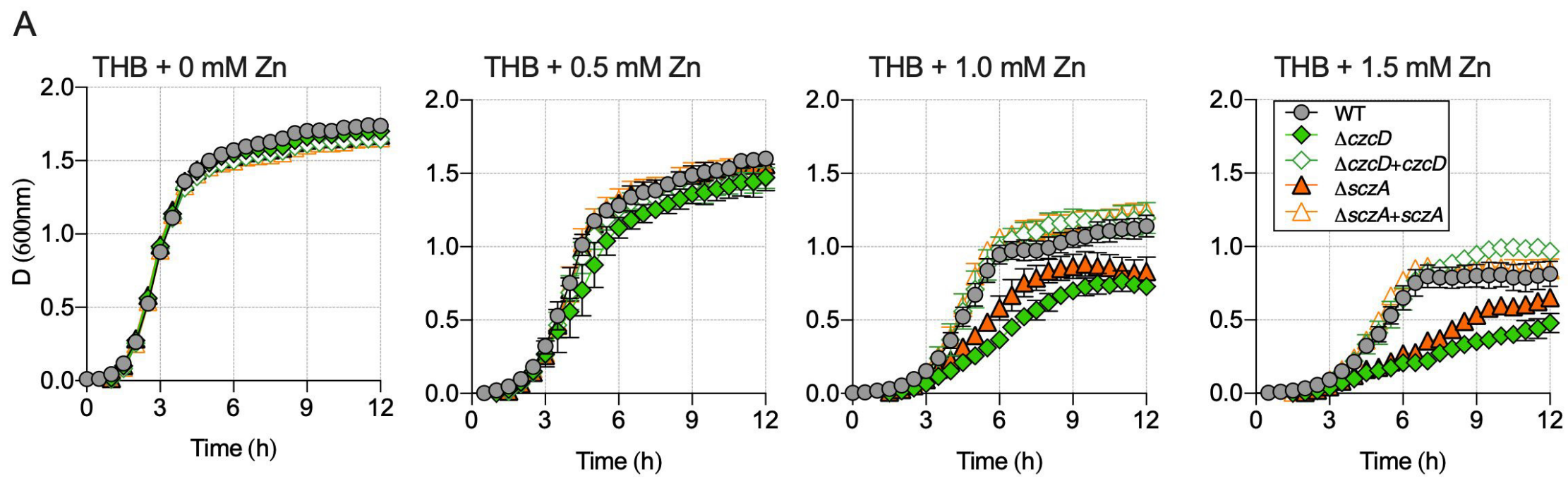

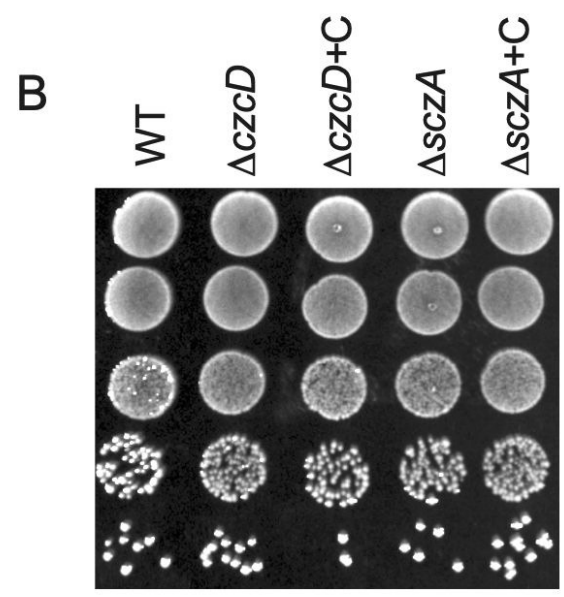

$0 \mathrm{mM} Z \mathrm{n}$

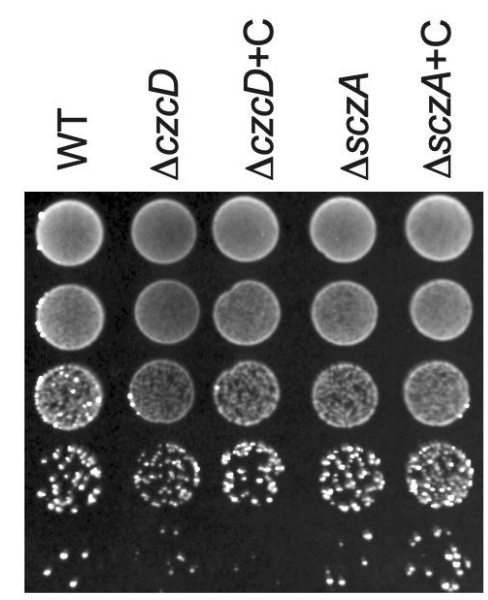

$0.5 \mathrm{mM} Z \mathrm{n}$

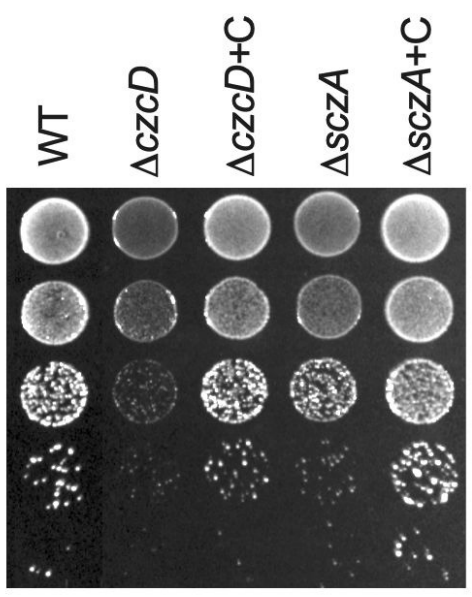

$1.0 \mathrm{mM} \mathrm{Zn}$

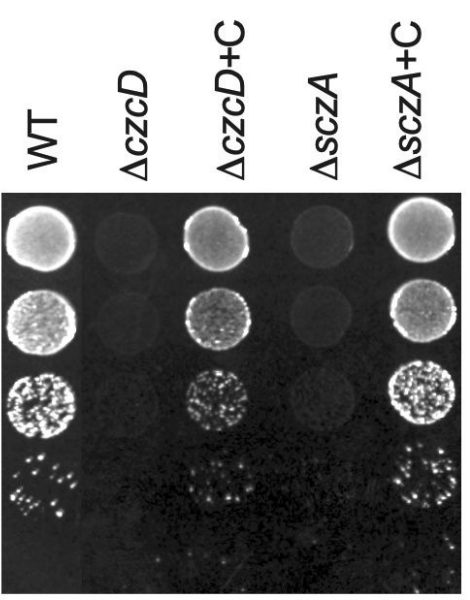

$1.5 \mathrm{mM} Z \mathrm{Zn}$

C
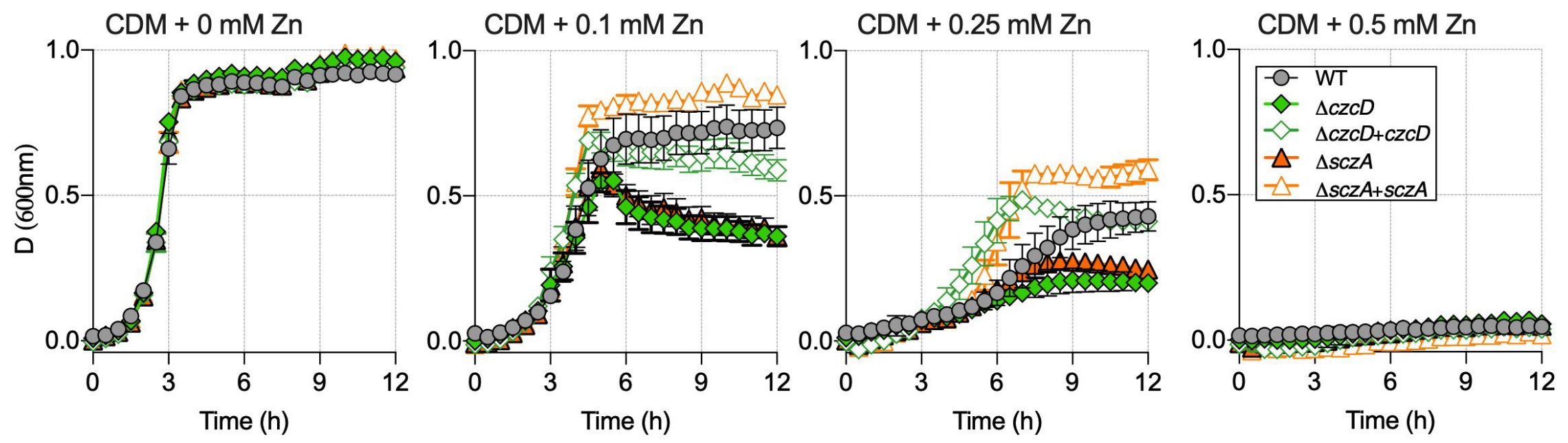
bioRxiv preprint doi: $h t t p s: / / d o i . o r g / 10.1101 / 2021.02 .04 .429868$; this version posted February 5,2021 . The copyright holder for this preprint (which was not certified by peer review) is the author/funder, who has granted bioRxiv a license to display the preprint in perpetuity. It is made available under aCC-BY-NC-ND 4.0 International license.
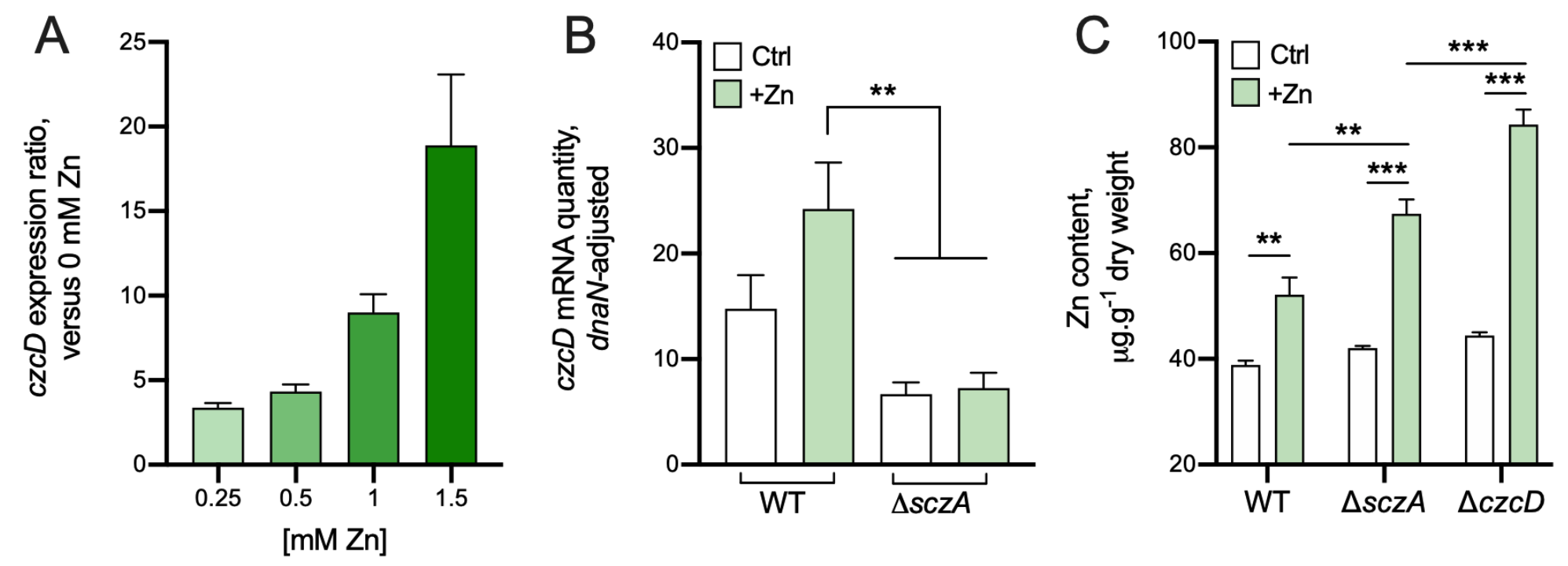
A

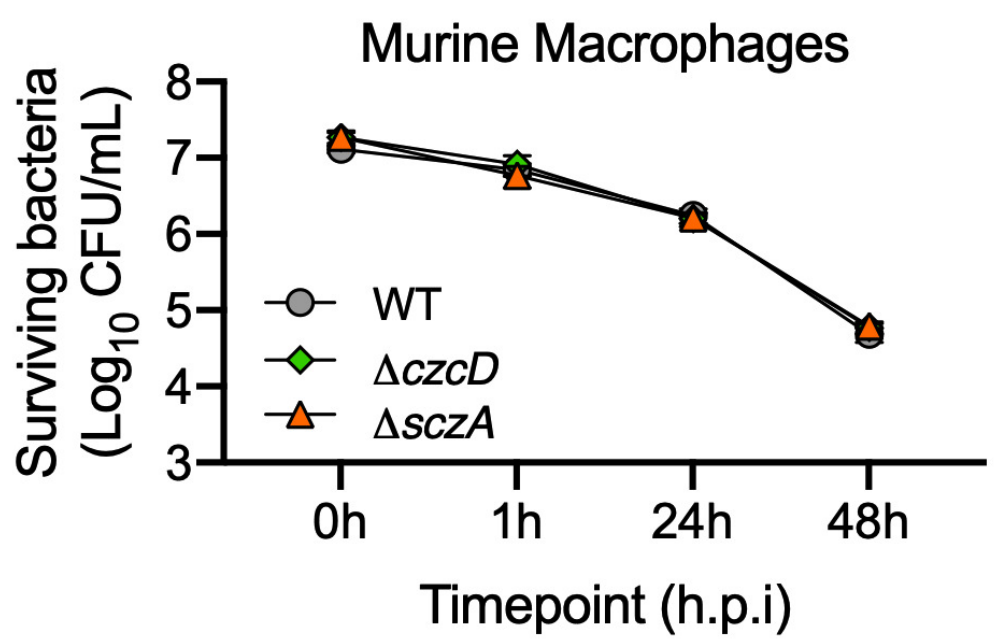

B

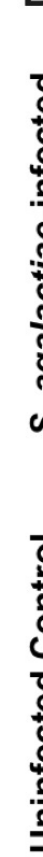

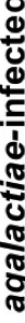

DNA stain Hoechst

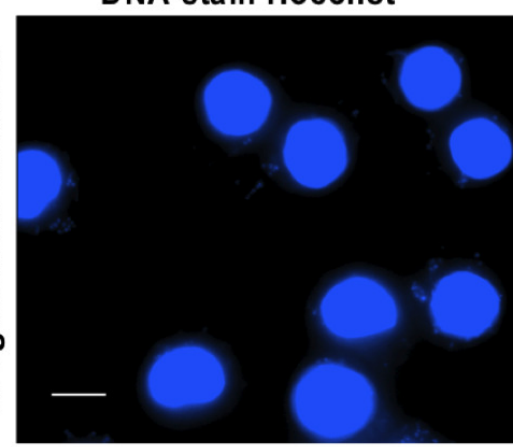

mCherry S. agalactiae

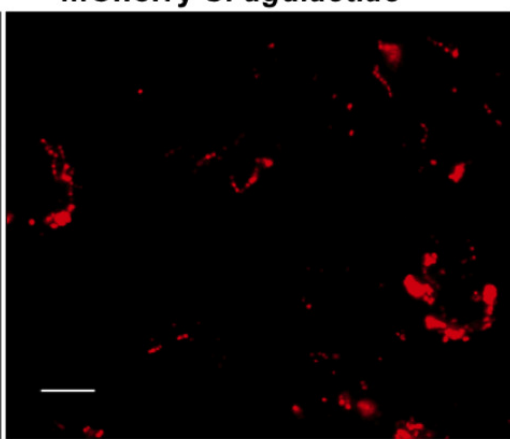

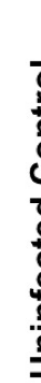
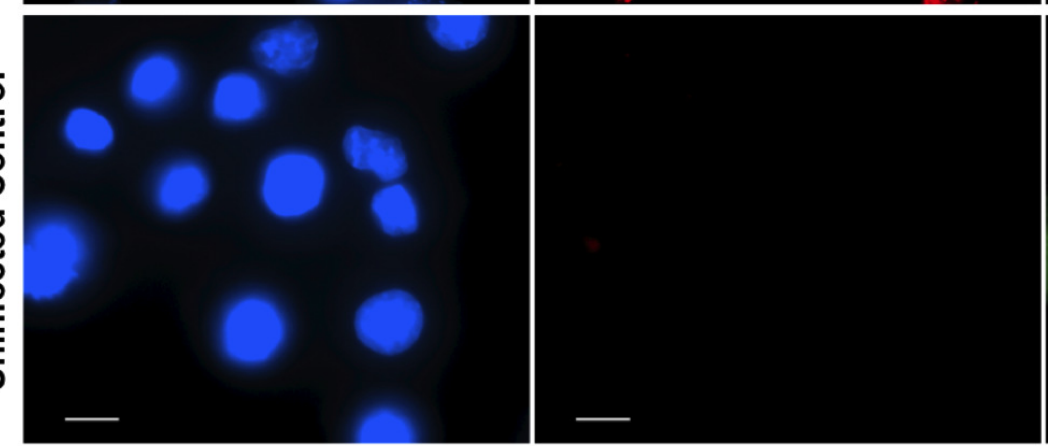

Human MDMs

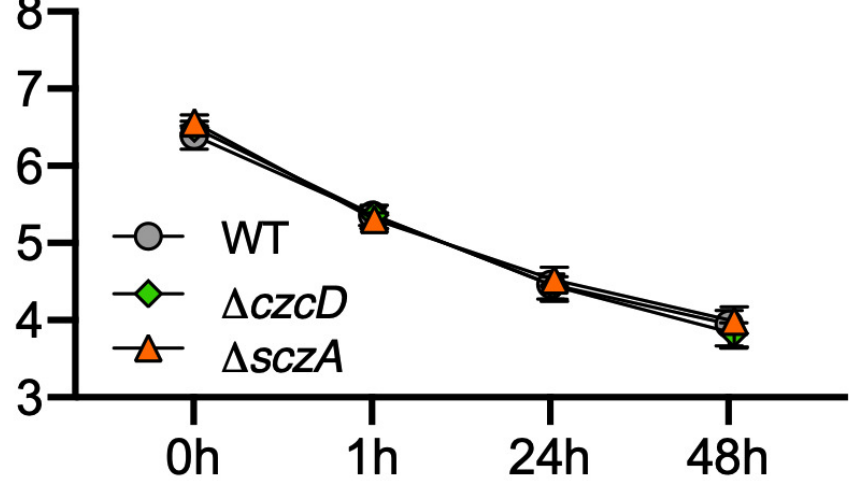

Timepoint (h.p.i)
Zn probe FluoZin-3-AM

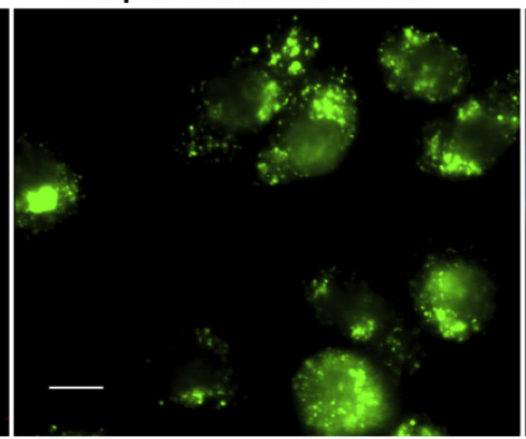

Merge

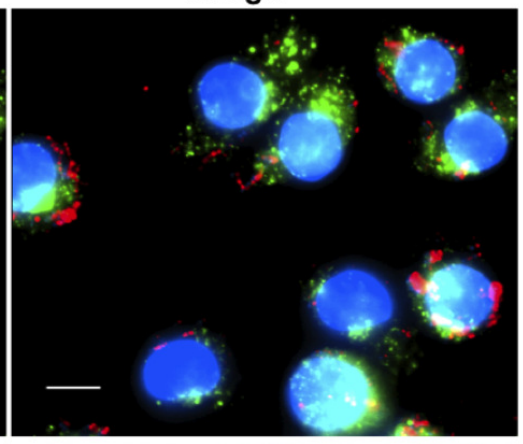

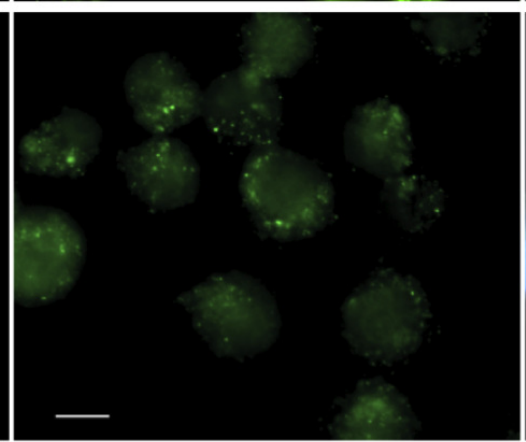

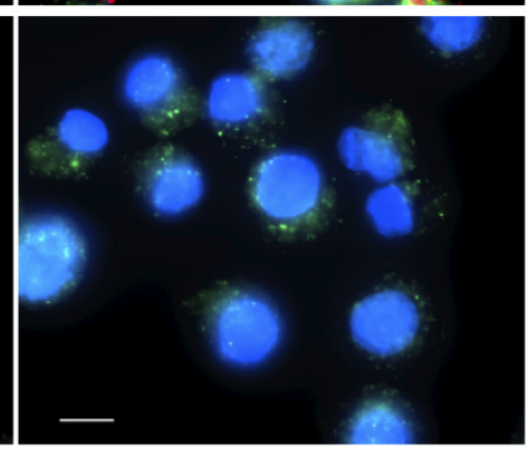


bioRxiv preprint doi: https://doi org/10.1101/2021.02 04 429868; this version posted February 5,2021 . The copyright holder for this preprint (which was not certified by peer review) is the author/funder, who has granted bioRxiv a license to display the preprint in perpetuity. It is made available under aCC-BY-NC-ND 4.0 International license.
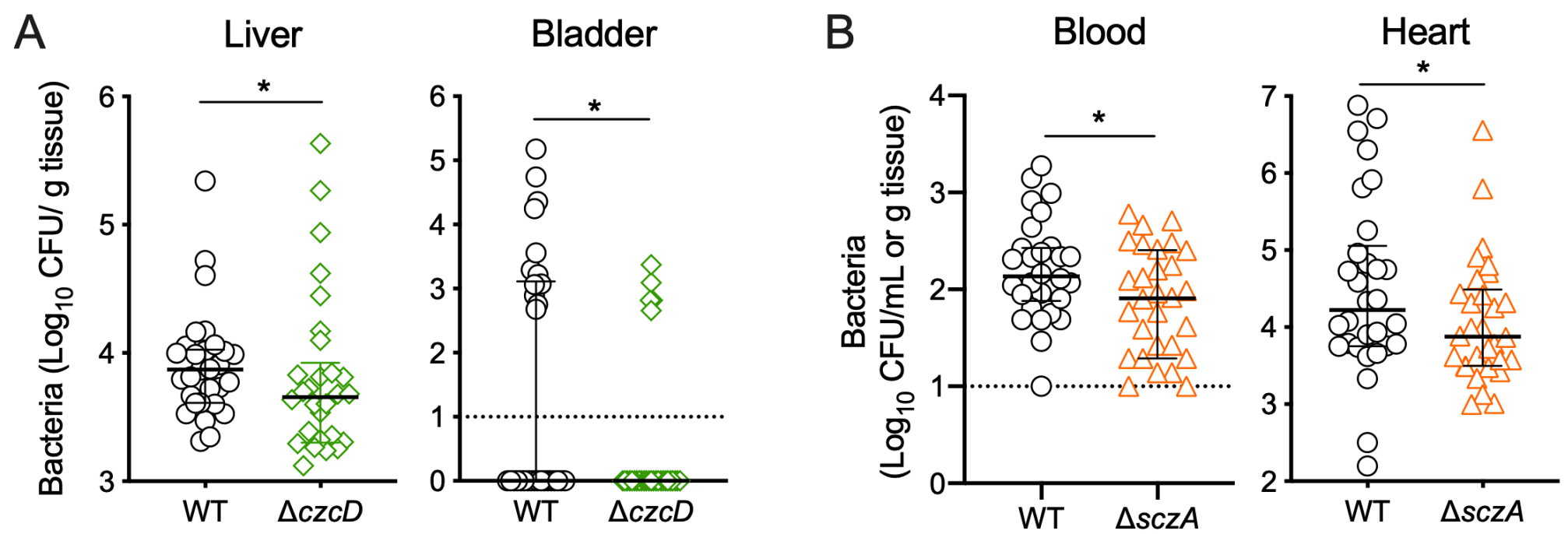
bioRxiv preprint doi: https://doi.org/10.1101/2021.02.04.429868; this version posted February 5, 2021. The copyright holder for this preprint (which was not certified by peer review) is the authqufustes

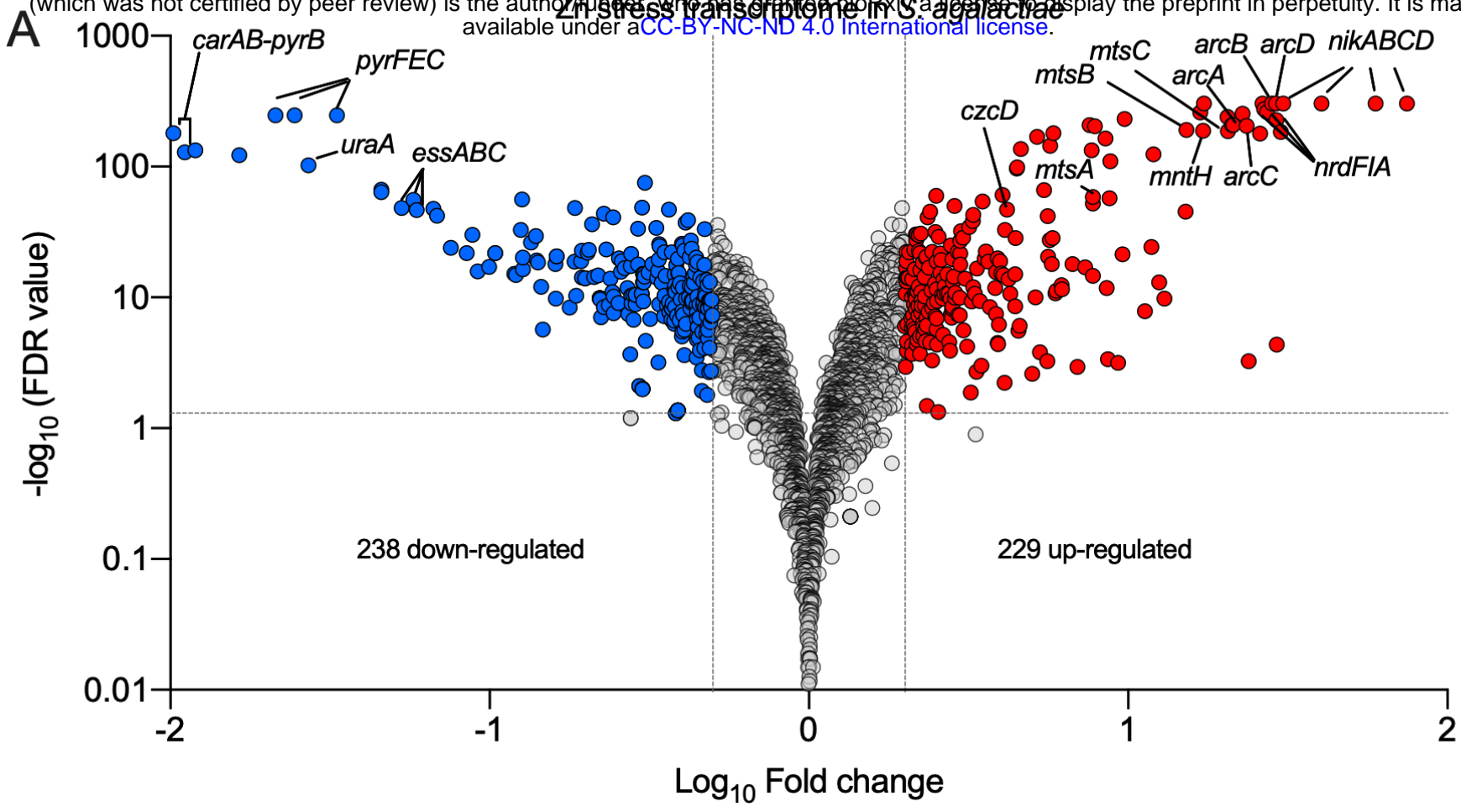

B Zn efflux Zn import

$\mathrm{Mn}$
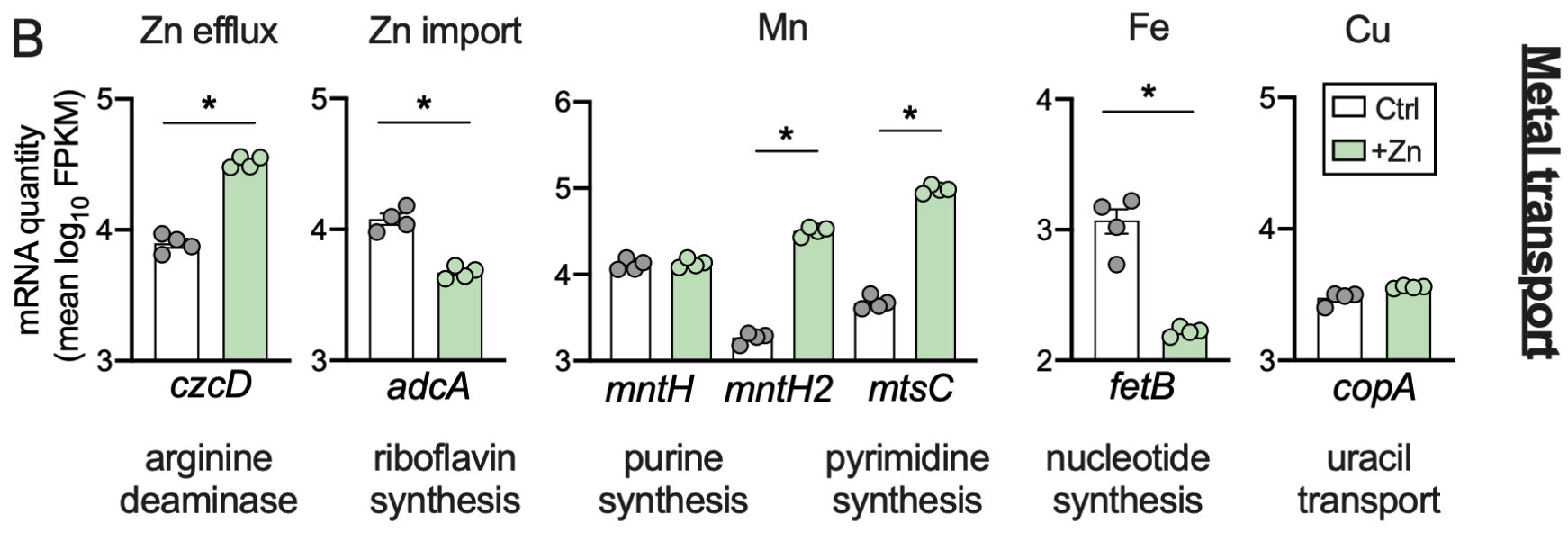

uracil
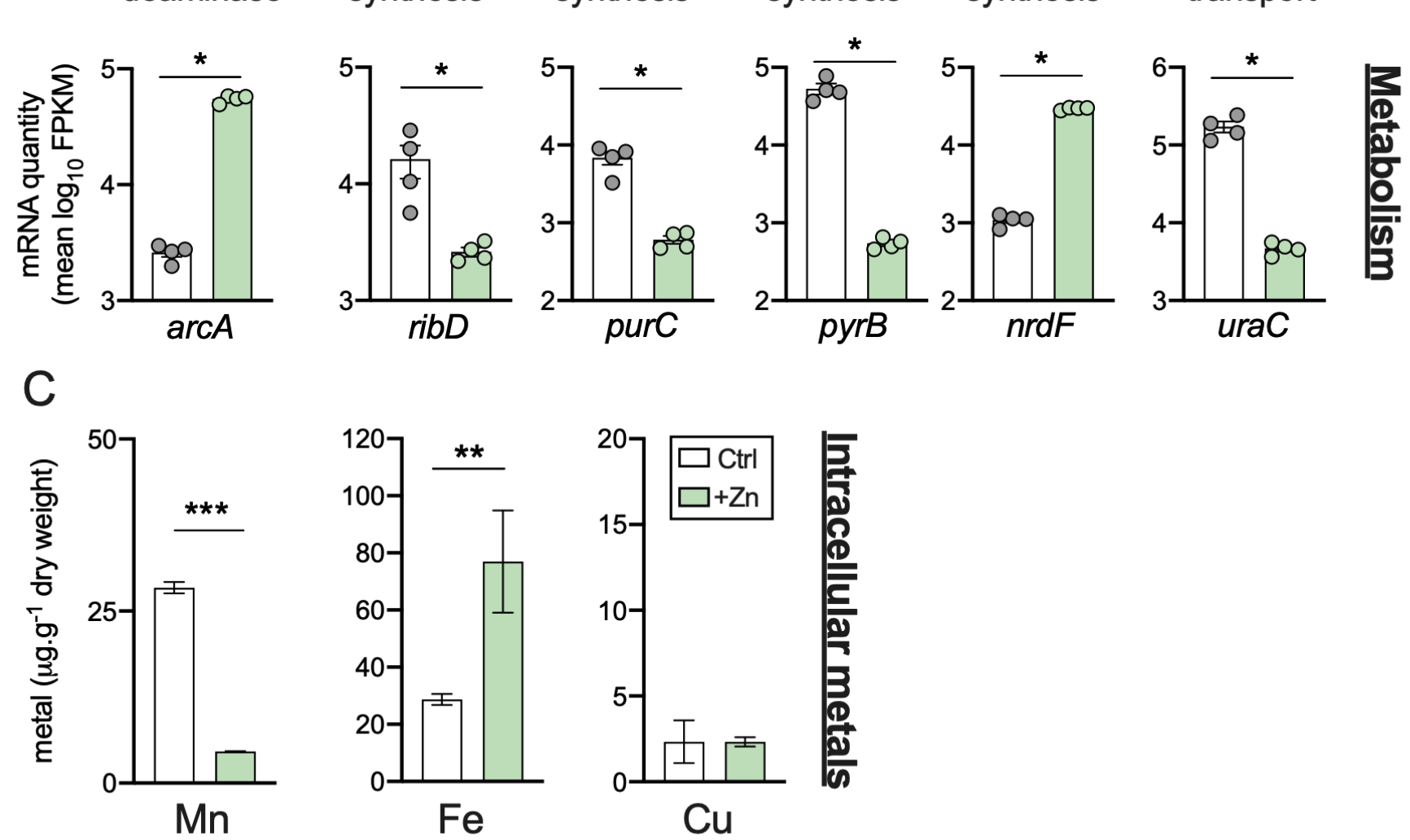
A

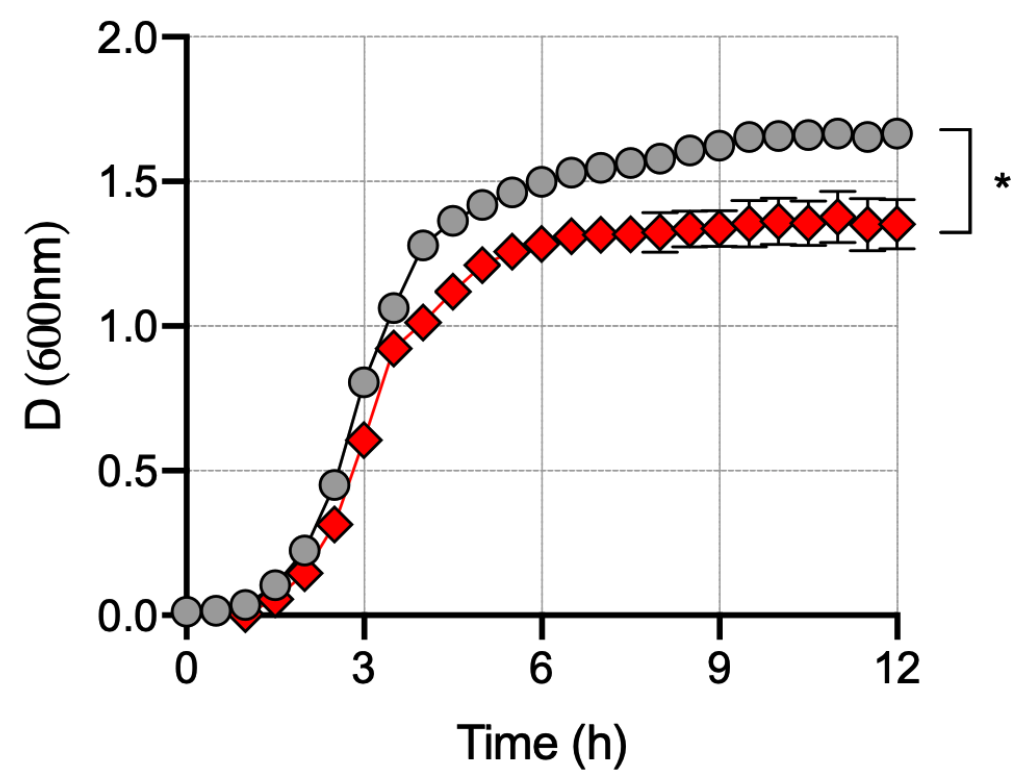

B

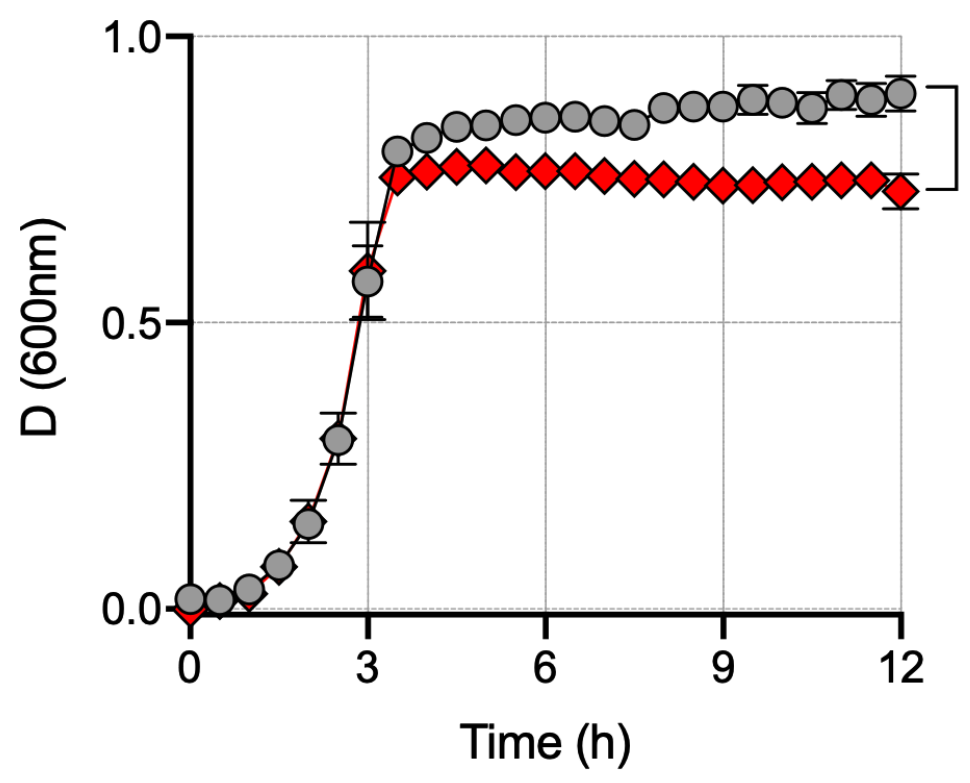

$\mathrm{THB}+1 \mathrm{mM} \mathrm{Zn}$

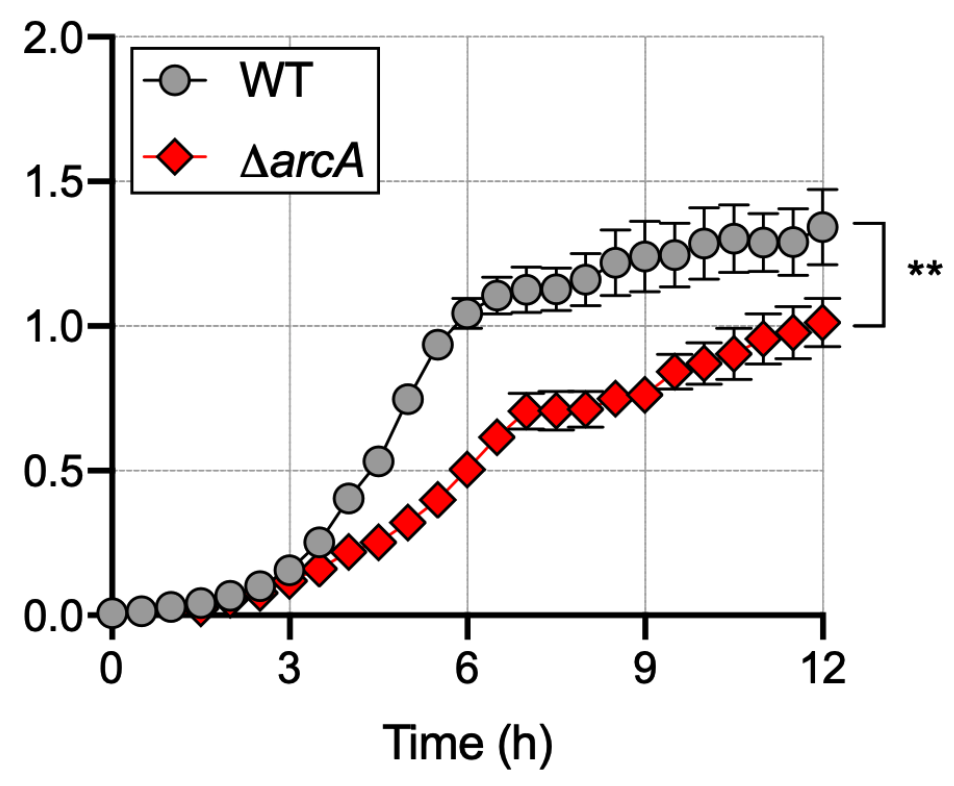

$\mathrm{CDM}+0.1 \mathrm{mM} \mathrm{Zn}$

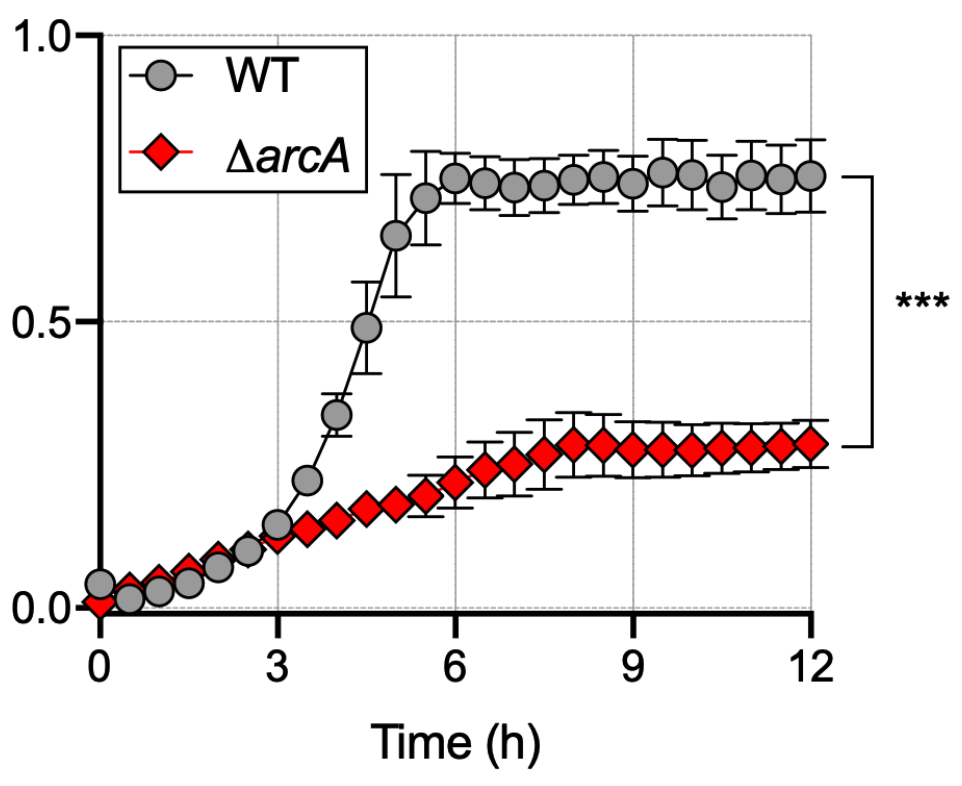




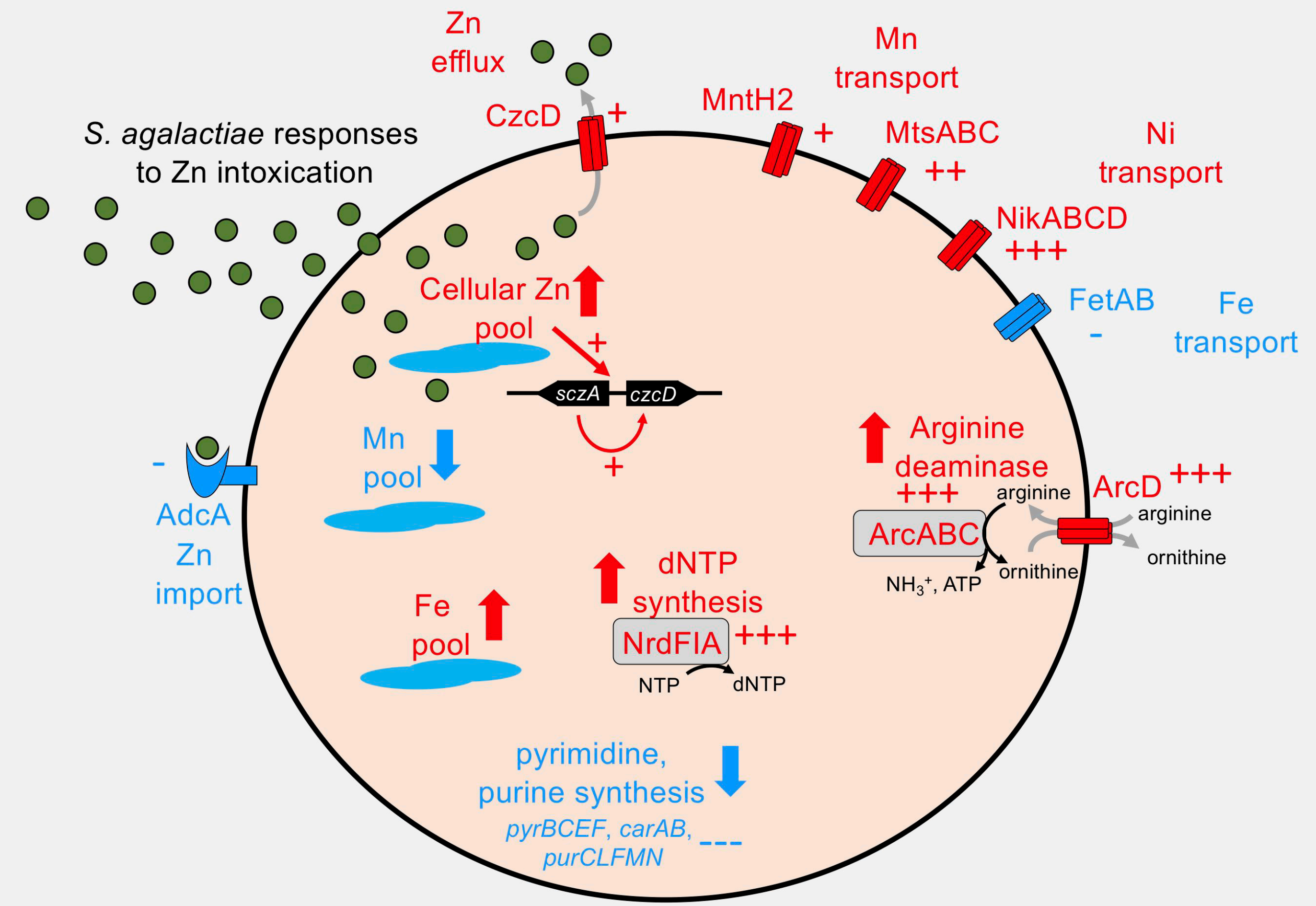

